\title{
Auditory representations for long lasting sounds: Insights from event-related brain potentials and neural oscillations
}

\author{
Annekathrin Weise ${ }^{1,2}$, Sabine Grimm², Johanna Maria Rimmele ${ }^{3,4}$, Erich Schröger ${ }^{2}$ \\ ${ }^{1}$ Department of Psychology, Ludwig-Maximilians-University Munich, Germany \\ ${ }^{2}$ Wilhelm Wundt Institute for Psychology -, Leipzig University, Germany \\ ${ }^{3}$ Department of Neuroscience, Max-Planck-Institute for Empirical Aesthetics, Germany \\ ${ }^{4}$ Center for Language, Music and Emotion, New York University, Max Planck Institute, Department of \\ Psychology, 6 Washington Place, New York, NY 10003
}

Address correspondence to:

Annekathrin Weise,

Department of Psychology, Ludwig-Maximilians-University Munich, Leopoldstraße 13, 80802

München, Germany

e-mail: annekathrin.weise@plus.ac.at

E-mail addresses of co-authors:

Sabine Grimm: sabine.grimm@uni-leipzig.de

Johanna Maria Rimmele: johanna.rimmele@ae.mpg.de

Erich Schröger: schroger@uni-leipzig.de 


\begin{abstract}
The basic features of short sounds, such as frequency and intensity including their temporal dynamics, are integrated in a unitary representation. Knowledge on how our brain processes long lasting sounds is scarce. We review research utilizing the Mismatch Negativity event-related potential and neural oscillatory activity for studying representations for long lasting simple versus complex sounds such as sinusoidal tones versus speech. There is evidence for a temporal constraint in the formation of auditory representations: Auditory edges like sound onsets within long lasting sounds open a temporal window of about $350 \mathrm{~ms}$ in which the sounds' dynamics are integrated into a representation, while information beyond that window contributes less to that representation. This integration window segments the auditory input into short chunks. We argue that the representations established in adjacent integration windows can be concatenated into an auditory representation of a long sound, thus, overcoming the temporal constraint.
\end{abstract}

Keywords: auditory edge, behavioral data, mismatch negativity, neural oscillations, sound representation, temporal integration 


\section{Introduction}

It is fascinating that humans are able to establish representations of spoken language that can be subsequently accessible to conscious retrieval even when the respective auditory information was initially neither attended nor task-relevant. The question of how complex sound representations emerge has challenged researchers for decades (for a review, see Cowan, 1984). Importantly, such processing is far from trivial: sound unfolds dynamically (and fleetingly) in time, with oftentimes no obvious cues for auditory boundaries. Thus, memory functions are indispensable to buffer the non-stationary input and to allow for its analysis. Specifically, incoming signals are decomposed into its sensory elements according to the feature selectivity of the processing units. The features (intensity, frequency, etc.) are processed separately in the peripheral and central auditory pathway before they are integrated at the level of the auditory cortex and aligned on the temporal axis into a unitary auditory representation ${ }^{1}$. This sound representation is an integrated description of the features of an auditory stimulus. It provides the informational basis for percepts (for reviews, see Nätänen \& Winkler, 1999; Schröger et al., 2014), for instance the sound of a door bell. For short sounds, the formation of an auditory representation has been extensively studied through behavioral (for reviews see Broadbent, 1958; Cowan, 1984, 1988) as well as electroencephalographic (EEG) / magnetoencephalographic (MEG) approaches (for reviews see Broadbent, 1958; Näätänen \& Winkler, 1999; Näätänen et al., 2011; Ritter et al., 1995; Schröger, 2007). However, sounds exceeding a duration of about $400 \mathrm{~ms}$ are rarely considered. The present review deals with the establishment of auditory representation for long sounds.

The present article reviews research dealing with the emergence of auditory representations, especially of long sounds lasting several hundreds of milliseconds. The formation of such auditory representations relies on so-called temporal windows that operate concurrently in the auditory system on different timescales and that segment the auditory input into distinct temporal chunks (e.g., Giraud \& Poeppel, 2012; Grimm et al., 2006; Luo \& Poeppel, 2007; Rimmele et al., 2015; Teng et al., 2016; Yabe et al., 2001; Weise et al., 2012a). As we highlight in section 2, the Mismatch Negativity (MMN; Näätänen et al., 1978) of the event-related potential (ERP) or its magnetoencephalographic counterpart (MMNm) is an ideal tool to probe auditory representations. In section 3 we briefly outline the prevailing view on how auditory representations for short sounds evolve. In section 4 we review empirical evidence highlighting that this account is not applicable for long lasting sounds that lack variation in their spectrotemporal features. Rather, MMN findings point to a temporal constraint in the auditory trace formation according to which mainly the initial $\sim 350 \mathrm{~ms}$ of the sound contribute to the trace formation. In contrast - as we argue in section 5 - this temporal bottleneck/constraint in the emergence of auditory representations is not an ubiquitous phenomenon but depends on the spectrotemporal content variations in sound. Based thereon, we argue that sound onset and

\footnotetext{
${ }^{1}$ In fact, in more natural scenes the formation of sound representations becomes even more complex as sounds usually do not occur as discrete physical events but rather overlap in time with events stemming from different sound sources However, for simplicity the current article will disregard the processing of concurrent sound information (for reviews see Alain, 2007; Micheyl \& Oxenham, 2010).
} 
certain acoustic features (e.g., amplitude modulations) of long lasting sounds initiate a temporal window of integration anew. This enables the formation of several auditory representations for initial and later parts of that sound. Also, we review a series of studies, mainly from our own research, that systematically address which key acoustic features aid overcoming the temporal constraint in trace formation. In section 6 , we show that the research of continuous speech processing and neural oscillations has important implications for the current framework. In section 7, we propose an updated framework on how auditory representations can be formed. This conceptual framework considers both, the duration as well as the acoustic features of sounds. We propose the view that several auditory representations resulting from adjacent temporal windows of integration can be bound into one unitary auditory representation at a higher hierarchical level. Finally, in section 8 we discuss challenges and future directions of studying the formation of auditory representations of long lasting sounds.

\section{Mismatch Negativity as an indicator for sound representations}

The MMN was initially observed in a classic 'oddball' paradigm by Ford and colleagues (1976), though it was Näätänen and colleagues (1978) who identified it as such and gave its name. In an oddball paradigm, a sequence of regularly occurring standard sounds is occasionally interrupted by rare deviant sounds. Deviants that slightly differ from standards in one feature (e.g., frequency or intensity) evoke MMN. This finding has been reproduced numerous times using different types of deviations (see below) and modified versions of the oddball paradigm (for reviews, see Näätänen et al., 2007; Paavilainen, 2013; Schröger, 2007; Sussman et al., 2014). The elicitation of MMN is indicated in the ERP as a more negative deflection for the deviant compared to the standard sound within 100 to $250 \mathrm{~ms}$ following deviant onset. In the deviant-minus-standard difference wave it appears as a negative deflection with frontocentral maximal amplitudes and, if a reference electrode is placed at the tip of the nose, with polarity inversion below the Sylvian fissure (for reviews, see e.g., Näätänen et al., 2007; Picton et al., 2000; Winkler, 2007). These and other findings suggest contributions of frontal and supratemporal auditory cortex generators (for reviews see Alho, 1995; Deouell, 2007; Escera et al., 2000).

From a conceptual point of view, the MMN has initially been interpreted as an indicator of a comparison process between the internal representation of the invariances inherent to the regular standard sounds and a newly incoming regularity-violating (deviant) sound (Näätänen, 1992; Sams et al., 1985). Current theories emphasize this comparison process to be predictive in nature (see, Winkler, 2007). In this view, the auditory regularities (e.g., in a simple case the repetitive occurrence of the same pitch) contribute to a 'predictive model'. Based on the regularity representations, predictions are derived about characteristics (e.g., the pitch) of the upcoming sound (Baldeweg, 2006; Bendixen et al., 2009, 2014; Grimm \& Schröger, 2007; Winkler et al., 1996; Winkler \& Schröger, 2015). These predictions are compared with the emerging unitary sound representation of the currently incoming sound. If the comparison results in a mismatch, the 
model needs to be updated. MMN reflects a prediction error signal, which goes hand in hand with the process of model updating (Winkler, 2007; Winkler \& Czigler, 1998; Winkler et al., 2009). Further, we like to mention that there exist several other conceptual accounts on MMN generation to those mentioned above, such as the "new afferent elements" account (e.g. Jääskeläinen et al., 2004; May \& Tiitinen, 2010, May et al., 1999). According to that account adaptation and (lateral) inhibition are responsible for the reduced activity to the regular standard. Indeed, animal research finds stimulus-specific adaptation occurring on multiple time-scales in auditory cortical neurons suggesting it is key to auditory sensory memory and can explain characteristic findings in the MMN literature (Ulanovsky et al., 2004; Yarden et al., 2022). It is important to mention that the different accounts on MMN generation are not necessarily contradictory or mutually exclusive. Rather, they may complement each other by providing a different conceptual level of explanation (Fitzgerald \& Todd, 2020). This is in line with a recent study that provides evidence for a functional and anatomic distinction between adaptation and deviance-detection processes (Parras et al., 2021). In any case, for the current framework, it is important to understand that the presence of MMN is a reliable indicator for the prior establishment of regularity representations (see below).

Importantly, MMN taps into sound representations which underlie perceptual units rather than the mere physical features of the sound. For instance, MMN has been found to be sensitive to perceptual phenomena such as masking (Winkler \& Näätänen, 1992; Winkler et al., 1993). Further, the amplitude of MMN depends on a difference in pitch rather than in spectral frequency (Tiitinen et al., 1994). Moreover, the minimal magnitude of change in a feature, which leads to MMN, roughly corresponds to the just noticeable difference (Amendo \& Escera, 2000; Kraus et al., 1999; for a review, see Näätänen \& Winkler, 1999). Also, the MMN is sensitive to duration deviants. The latter requires that the offset of a sound is related to the onset of that sound, assuming that onset and offset are integrated into one overarching representation, thus, allowing the detection of shorter (Näätänen et al., 1989, 2004; Grimm et al., 2004) or longer sounds (Colin et al., 2009). Further, when two successive deviants are separated by $300 \mathrm{~ms}$, two MMNs are elicited, while only a single MMN is elicited when the deviants are separated by only $150 \mathrm{~ms}$, and thus, are putatively integrated into one perceptual unit (Sussman et al. 1999). Studies showing that MMN is elicited by violations of feature conjunction regularities (e.g., Paavilainen et al., 2001) suggest that the underlying predictive model is based on feature-integrated representations.

While MMN is not the only component of the ERP that is sensitive to rare and unexpected changes in the auditory environment, MMN seems to be the earliest component, which is associated with unitary sound representations. The amplitude of the middle-latency response (MLR; 10 to $50 \mathrm{~ms}$ after sound onset; Picton et al., 1974) can be modulated by single feature deviants in an oddball paradigm (Althen et al., 2011; Grimm et al., 2011; Leung et al., 2012; Recasens et al., 2014a). Yet, the neural traces underlying the MLR have not been proven to tap into integrated memory representations (for a review, see Näätänen \& Winkler, 1999). This is underlined by studies suggesting that deviance-related effects in the MLR time range cannot 
be found in paradigms using pattern regularities (Cornella et al., 2012; Recasens et al., 2014b) or regularities regarding the combination of different sound features (Althen et al., 2013). Other ERP components that precede the MMN, such as the anterior component of the N1, however, have been related to the trace formation process mediated by the temporal window of integration (Loveless \& Hari, 1993; McEvoy et al., 1997).

To sum up, sound features seem to be represented by feature-specific neural populations at different hierarchical levels and at multiple time scales in the auditory cortex (e.g., reflected in the time range of MLR, N1, and MMN). Temporally and feature-integrated auditory percepts seem to be first represented by neural traces underlying MMN generation. However, one should keep in mind that MMN is rather the outcome of the comparator mechanism than a direct correlate of sound representation.

\section{The prevailing view on how auditory representations evolve}

Since the middle of the 20th century, behavioral approaches and later on electrophysiological measures have been used to study how auditory representations evolve (Atkinson \& Shiffrin, 1968; Broadbent, 1958; Cowan, 1984, 1988, 2008; Massaro, 1970; Näätänen \& Winkler, 1999; Schröger, 2007). To understand the formation of auditory representations, one should consider the whole process starting from the moment when the sound arrives at the ear. Since sound evolves over time, acoustic information enters the ear as a time-variable signal. It is processed in the periphery of the ascending auditory pathway with high temporal resolution. Different stations of the pathway analyze the acoustic features of the input, such as spectral composition, intensity, and interaural differences with low time-constants (see e.g., Eggermont, 2001, for a review). Metaphorically speaking: the sound is 'decomposed' into its individual elements at lower processing levels. To perceive or retrieve the input as a unit rather than individual elements, the acoustic features belonging to a certain sound event need to be integrated and related over time. It is assumed that the onset of a sound initiates several distinct processes, which analyze and extract sound features and bind the outcome of these feature analyzers via the temporal window of integration (for a review see Näätänen \& Winkler, 1999, p. 845ff).

This integration function can be regarded as a memory function as it enables the binding of preceding and subsequent information belonging to the same event. In fact, it has been linked to the short literal phase (Cowan, 1984) or pre-perceptual store (Massaro, 1970) of auditory sensory memory $\left(\mathrm{ASM}^{2}\right)$. It provides the specific information contents for the sound percept (which may be conscious or preconscious, depending on whether the input also succeeds in exceeding the attention-trigger threshold controlled by separate mechanisms'; Näätänen \& Winkler, 1999, p. 847). This supports the notion that sensory memory

\footnotetext{
${ }^{2}$ ASM is a type of memory that differs from other stores (e.g., short term memory, working memory) in that it operates even when the sensory input is not attended (Broadbent, 1958). Further, it processes exclusively modality-specific (i.e., auditory) information. Information of other modalities are processed in separate stores (e.g., iconic memory buffers visual information; Neisser, 1967). 
and perception are intrinsically intermingled in audition. In fact, 'there is no definite boundary between them', and - importantly - it is not that sensory memory is a consequence of perception but, vice versa, 'perception appears to be a consequence of memory' (Demany \& Semal, 2007, p. 77). Perceptual phenomena resulting from temporal integration are, for example, 1) loudness summation, according to which the perceived loudness of a sound increases as stimulus duration increases up to about $200 \mathrm{~ms}$ (e.g., Zwislocki, 1969), or 2) the duration overestimation phenomenon. According to the latter, the duration of sounds shorter than 130 to $180 \mathrm{~ms}$ is typically overestimated, whereas the duration of longer stimuli is perceived more or less accurately (e.g., Efron, 1970). This view on ASM as an information process function that is organically interwoven with other cognitive faculties (rather than a separation of storage(s) and information processing) is highly compatible to embedded-process models of (working) memory (Cowan, 2005; Oberauer, 2002; Postle, 2006) and to the more general hierarchical process memory conceptualisation (Hasson et al., 2015).

Perceptual phenomena such as loudness summation or duration overestimation should, however, not be misinterpreted in that temporal integration results in a general loss of temporal information (Näätänen, 1995). In fact, the notion of a 'holistic' representation, which contains a spectral average over time (Cowan, 1984), was disproved numerous times. Rather, the spectrotemporal information of a sound is precisely aligned on the time axis within the temporal window of integration. This was, for instance, shown by MMN studies utilizing the 'deviance-position' approach - i.e., paradigms in which only a part of the deviant sound differs from the standard, thus the deviation occurs at a specific temporal position within a sound (Grimm \& Schröger, 2005, 2007; Grimm et al., 2006; Hoonhorst et al., 2012; Yabe et al., 2001, 2004). For example, the standard stimulus could be composed of five concatenated $(<40 \mathrm{~ms})$ brief tonal segments of constant frequency, while deviants differ from the standard in that either the second, third, fourth, or fifth segment is missing (Yabe et al., 2001). Importantly, MMN is obtained time-locked to the respective missing (or mismatching) tonal segment instead of time-locked to the offset of the deviant sound (Grimm \& Schröger, 2005, 2007; Hoonhorst et al., 2012; Yabe et al., 2001, 2004). Also MMN to feature changes (instead of omissions) within tonal patterns are time-locked to the change (e.g., Schröger et al., 1994), when two changes occur within a single pattern two MMNs time-locked to each change are elicited (Schröger, 1994), and MMN is also elicited when two elements in a pattern with only the duration of the elements differing are exchanged (Winkler \& Schröger, 1995). Similar conclusions could also be drawn from reaction times measured in comparable behavioral approaches (e.g., Timm et al., 2011). This shows that the order of the auditory information entering the integration process is preserved, even though the active access to temporal order information might be restricted by a central mechanism (not the sensory channel per se), as time intervals of about $20 \mathrm{~ms}$ between tones are needed to establish correct temporal order judgments (e.g., Hirsh, 1959). The temporally precise representation of sound features is, actually, very important given that meaningful units such as speech sounds (e.g., phonemes in syllables) become distinguishable from each other on the basis of their precise feature mapping. In this context we also want to briefly discuss an interesting phenomenon, called the phoneme restoration effect (Greenberg \& Arai, 2001; Kiss et al., 2008; 
Saberi \& Perrott, 1999; Ueda et al., 2017). Speech signals, which were cut into 20-50 ms segments and time-reversed, stayed fully intelligible, while intelligibility decreased with longer segment duration. At a first glance, these findings seem to be at odds with the MMN data supporting an accurate and literal temporal representation of sounds. However, the duration up to which time reversed segments were still intellegible depended on whether participants were native speakers or not (Kiss et al., 2008). Thus, it has been suggested that phoneme restoration within a window of $\sim 20-50 \mathrm{~ms}$ does not indicate loss of temporal information, but rather might indicate a buffer for reorganizing temporal order of events according to linguistic information (Kiss et al., 2008; Ueda et al., 2017). The findings are in line with a multi-time scale model of speech perception, suggesting a short 'temporal integration window' 20-40 ms for analyzing rapid spectral changes, such as in consonants (e.g., Giraud \& Poeppel, 2012; Poeppel, 2003; Sanders \& Poeppel, 2007; see also: Rimmele et al., 2015).

From a perspective of ASM models, in order to avoid information loss due to the brief life-time of the short phase of ASM, the outcome of the temporal integration process (i.e., the sound representation that corresponds to the contents of the percept) can be stored in the long phase (Cowan, 1984) or synthesized store (Massaro, 1970) of ASM. It has a life-time of up to several seconds (Crowder \& Morton, 1969; Watkins \& Todres, 1980). It contacts long term memory, which enables sound recognition (Massaro, 1975) and allows that the sound representation is accessible for higher cognitive functions enabling, for instance, sound discrimination, information retrieval, and understanding of speech. A demonstrative example from everyday life is our ability to voluntarily extract the meaning of an initially unattended question when allocating attention to it with a certain delay in time (for empirical evidence from dichotic listening paradigms, see Broadbent, 1958).

To sum up, the original model on the formation of sound representation assumes that sound onset initiates a temporal window of integration that binds the outcome of the feature analyzers and is confined to approximately $200 \mathrm{~ms}$ in duration. The resulting trace provides the specific information contents for the auditory percept and can be stored up to several seconds being accessible for higher cognitive functions such as information retrieval.

\section{A temporal constraint for the formation of auditory representations}

Many sounds in everyday life exceed the time-span of the temporal integration function. Thus, the emergence of their neural / mental representations cannot easily be explained by the original model (Näätänen \& Winkler, 1999). Recent research corroborates this view, so there is a need for an upgrade of the original model on the formation of auditory representations (Grimm et al., 2004; Grimm \& Schröger, 2005; Näätänen et al., 2004; Timm et al., 2011; Weise et al., 2010).

Studies using the 'deviance position' approach introduced deviants which were not completely different from standards, but rather contained a brief interval of deviating content within the sound. Crucially, within 
this approach deviants can contain the same feature violation, yet positioned at varying time points relative to sound onset (Grimm \& Schröger, 2005; Grimm et al., 2004, 2006; Näätänen et al., 2004; Hoonhorst et al., 2012; Timm et al., 2011; Weise et al., 2007). In one of these studies (Grimm \& Schröger, 2005), MMN was measured to a short frequency modulation that occurred either 100, 200, $300 \mathrm{~ms}$ etc. (up to $900 \mathrm{~ms}$ ) following the onset of rare deviant sounds, which otherwise resembled the 1000-ms standard sounds of constant frequency. A distinct MMN was elicited to deviances occurring within the first $300 \mathrm{~ms}$ following sound onset. Importantly, when the deviance occurred $400 \mathrm{~ms}$ or later, MMN was strongly attenuated or even absent. This so called temporal distance effect on MMN amplitude has been reported numerous times (Grimm \& Schröger, 2005; Grimm et al., 2004; Hoonhorst et al., 2012; Timm et al., 2011; Weise et al., 2010; Yabe et al., 2001). Crucially, it generalizes to different types of deviance, e.g., when the deviance was a brief frequency modulation (Grimm \& Schröger, 2005; Hoonhorst et al., 2012; Timm et al., 2011; Weise et al., 2007), a duration decrement (Grimm \& Schröger, 2005; Grimm et al., 2004, 2006; Näätänen et al., 2004), or even a feature exclusion (Hoonhorst et al., 2012). The fact that similar decay functions are observed for different feature changes substantiates the view that the decrease in MMN amplitude is related to a temporal constraint for unitary sound representations rather than to the processing or representation of specific stimulus information (e.g., the representation of the frequency modulation per se, see Grimm et al, 2006). This temporal constraint in sound representation has been attributed to the restricted capacity of the short phase of the auditory store and its integration function (Cowan, 1984; Grimm \& Schröger, 2005; Grimm et al., 2006) $)^{3}$.

Findings from the 'deviance position' approach have inspired a modification of the memory-trace formation model originally proposed by Näätänen \& Winkler (1999). In the original model it is assumed that the onset of a sound (e.g., a short tone pip) initiates several distinct processes, such as the extraction and analysis of the sound features as well as the integration of the feature analyzers' outcome into an auditory representation extending along the time dimension. Following the integration phase, the auditory representation is held in the synthesized store of ASM and then starts to decay.

Grimm \& Schröger (2005) modified the model considering the formation of auditory representations for long lasting (time-invariant) sounds. They suggest that input features which appear close (in time) to sound onset fall into the optimal phase of feature binding and temporal integration (lasting approx. $200 \mathrm{~ms}$ ) whereas sound portions that are further away from stimulus onset might contribute less to the auditory representation. If the temporal distance between a specific sound portion and the stimulus onset is larger than approx. $350 \mathrm{~ms}$ its contribution might have tapered out - to a degree that a feature change affecting such a late portion of a newly incoming sound will not elicit MMN anymore. In fact, the exact time-limits of the integration process might depend on various factors. MMN findings suggest, for example, that the

\footnotetext{
${ }^{3}$ Note that some studies report a significant MMN even for deviations occurring beyond the critical 350-ms (e.g., Näätänen et al., 2004). Crucially and in favor of our argumentation is the fact that MMN for deviations occurring within the temporal window of integration were significantly larger compared to deviations outside that critical period. 
integration process depends not only on temporal but also on the spectral aspects of the stimulus. More precisely, it was postulated that with increasing spectral disparity between sequential elements of the acoustic input the size of the integration window decreases. Thus, what is integrated into an auditory representation also depends on the stimulus characteristics. A more precise description of the trace formation process would, therefore, be 'spectrotemporal' integration, highlighting its two-dimensionality (Shinozaki et al., 2003). Further support that the time span of the temporal window of integration is not fixed but rather adaptive comes from MMN data suggesting that the overall integration period is longer in children than in adults (Wang et al., 2005a). Moreover, the size of the integration window seems to depend on musical experience with shorter integration windows for musical laypersons than professionals (Rüsseler et al., 2001). Thus, automatic trace formation depends largely on factors influencing the time span of the temporal window of integration. ${ }^{4}$

One might argue that the strongly reduced MMN to late deviances within time-invariant sounds (e.g., Grimm et al., 2006) is not due to the temporal constraint in auditory representation but because the auditory system is missing the critical stimulus information characterizing the deviation. Importantly, this alternative explanation can be ruled out by several facts. 1) Electrophysiological indicators such as the sustained potential (Näätänen \& Picton, 1987; Picton et al., 1978), which is observable in the ERP throughout the presentation of a continuous long lasting (>500 ms) sound (e.g., Weise et al., 2012b, 2018) reflecting its sensory encoding (Picton et al., 1978), suggest that feature extraction is unimpaired even for long lasting sounds. This view is corroborated by the elicitation of the mainly stimulus-driven P1, N1, or P2 components (Hyde, 1997; Martin et al., 2008; Näätänen \& Picton, 1987) to auditory changes within long lasting sounds. The offset of a (>500 ms) long lasting sound (Näätänen \& Picton, 1987; Picton et al., 1978; Weise et al., 2012a; Yamashiro et al., 2009, 2011), and a late (>500 ms) occurring change in frequency (Dimitrijevic et al., 2008) or intensity (Dimitrijevic et al., 2009) within an otherwise time-invariant sound evoke those transient ERPs. Thus, the temporal constraint in the formation of auditory representation is less likely the consequence of impaired or less precise processing at an earlier stage in the auditory ascending pathway which is responsible for feature extraction. 2) Additional support comes from behavioral data showing that deviation in both duration and frequency occurring later than $300 \mathrm{~ms}$ following sound onset can easily be discriminated when the sounds are attended (Hoonhorst et al., 2012; Timm et al., 2011). That is, behavioural performance highly exceeded chance level (and in some cases even reached ceiling level) irrespective of the temporal distance of the deviance relative to sound onset (Weise et al., 2010; Yabe et al.,

\footnotetext{
${ }^{4}$ Indeed, trace formation depends also on cognitive factors such as attention. If sounds are attended, cognitive processing capacities become available. Consequently, the processing of temporal properties of a sound is significantly improved, especially when attention is directed explicitly to the temporal dimension. Unlike automatic processing, attention seems to allow forming traces over a much longer time period (Grimm \& Schröger, 2005). This might be due to an attention-dependent binding of sensory information. Alternatively, the ability to integrate acoustic input over a larger temporal distance under attention could be explained by the assumption of an additional process emerging at a next-higher level, where it then relates the contents of several, consecutive auditory representations into one unified auditory representation (Grimm, 2006).
} 
2004). Therefore, the bottleneck in forming a perceptual entity seems rather to be a consequence of the restricted capacity of the integration process.

To sum up, MMN research applying the 'deviance position' approach uncovered a temporal constraint in automatic trace formation for long lasting, time-invariant sounds. This led to an updated model on the emergence of auditory representations. According to that, sound onset initiates feature extraction and feature binding into an auditory representation within a period of about $200 \mathrm{~ms}$. Sound parts that fall outside that integration window might contribute less to the auditory representation. The contribution of sound parts that occur later than approx. $350 \mathrm{~ms}$ following sound onset might have tapered out. The exact time-limits of the integration process seem to rely on various factors.

\section{Auditory representations for long time-variant sounds due to auditory edges}

Interestingly, the temporal constraint in automatic trace formation seems not to apply ubiquitously. In fact, auditory memory functions allow humans to recall spoken language - exceeding the capacity of the temporal window of integration - even when it was initially not attended. This everyday experience receives empirical support from the outcome of a dichotic-listening paradigm (Broadbent, 1954). Participants listened to different digits on different ears at the same time (e.g., 7-2-3 on the right and 1-4-5 on the left ear). Speech rate was two digits per second on both ears. The listener was required to reproduce all six digits in any order they chose. Importantly, this task was solvable and the order of reproduction was either, 7-2-3-1-4-5, or 1-4-5-7-2-3 and never of the type 7-1-2-4-3-5. That is, the three digits from the attended ear were reported first, followed by the three digits from the initially unattended ear. This implies that also the latter three digits were processed on their arrival and held in memory until attentional resources were available to recall them.

Further support for full-fledged auditory representations of long sounds comes from numerous MMN studies utilizing time-variant sounds. Those studies found MMN elicited by a deviance that occurred considerably beyond the critical 350-ms following sound onset (e.g., Atienza et al., 2003; van Zuijen et al., 2004). This implies that even such late sound information can contribute to the evolving auditory representation. In one of those studies MMN was measured to a rarely occurring fifth tonal element within an otherwise regularly occurring four-tone pattern (van Zuijen et al., 2004). The tonal elements were separated by an onset-to-onset interval of $187.5 \mathrm{~ms}$. Within each sound pattern, tonal elements shared the same frequency, whereas across sound patterns the frequency values varied. The elicitation of MMN to the 5th tonal element, thus occurring $750 \mathrm{~ms}$ following pattern onset, reflected the non-decayed sound representation for such pattern stimuli.

Corroborating indices for an adequate representation of more complex sounds stems not only from studies utilizing pattern stimuli but also from research exploiting speech sounds. They sometimes reported a 
distinct MMN to deviances occurring later than 350 ms following stimulus onset (e.g., Barry et al., 2009; Pulvermüller et al., 2001, 2004). ${ }^{5}$ For instance, Vidal and colleagues (2019) observed an MMN to occasional changes in a set of regular pseudowords, when either their second syllable (starting $325 \mathrm{~ms}$ after stimulus onset) or the third syllable (starting $650 \mathrm{~ms}$ after stimulus onset) were affected by the change. Interestingly, the deviants affecting the third syllable of the pseudowords elicited even larger MMNs than deviants affecting the earlier position. At a first glance, these findings appear to be contradictory to the deviance-position effect that has been observed with time-invariant standard sounds, where deviations occurring later in the sound elicit an MMN of (strongly) reduced amplitude. However, this seeming contradiction can be reconciled via the following explanation: This difference in the direction of the effect could be due to the involvement of lexical processing, which allow for a hierarchical chunking of the pseudowords' representations (e.g., level of word representation vs. level of single syllable representation and their transitions), which will not be the case for time-invariant sounds of similarly long duration.

Based on the findings reviewed in this section it can be implied that adequate representations for time-variant sounds can be formed even beyond $350 \mathrm{~ms}$, while the trace formation process for time-invariant sounds is restricted to that critical temporal border. Accordingly, time-varying characteristics within long lasting sounds seem to play a crucial role for automatic trace formation. We set up the hypotheses that certain features within time-varying sounds initiate temporal integration anew similar to sound onset allowing to overcome the temporal constraint in forming auditory representations (for details see section 6). This notion is in line with the putative functional significance of the temporal window of integration, which is to segment the auditory perceptual world (Bregman, 1994; Näätänen \& Winkler, 1999).

In a series of studies we systematically tested our hypothesis that an auditory transient within a sound initiates the integration process. Our studies took advantage of an approach, which allowed us to directly compare MMN to a late deviance within time-variant and time-invariant sounds. In one of those studies, stimuli lasted 650-ms and were of constant frequency (Weise et al., 2007). In three different conditions the sinusoidal tones were either unstructured or contained a brief transient change / auditory edge (i.e., noise burst or gap) starting at about $340 \mathrm{~ms}$ following sound onset. In all conditions, the deviance (a 50-ms frequency modulation) occurred at 550-ms after the onset of the tone. As hypothesized, MMN occurred in response to the late deviance within structured sounds, while no MMN was elicited by the deviance within time-invariant tones. This finding is in line with our hypothesis that the transient (gap, noise burst) initiates

\footnotetext{
${ }^{5}$ Even though some of those studies using speech stimuli (and tonal counterparts) found a smaller MMN amplitude for later deviance positions this does not contradict our argumentation. This is because 1) the MMN to later deviance positions was of distinct magnitude and, importantly, statistically present (e.g., Partanen et al. 2011; Sussman et al., 2004). 2) The temporal position effect on MMN amplitude did not resemble the one we observed in our studies (Grimm et al., 2006; Weise et al., 2010, 2012) as it rather showed a 'U-shape' for three different deviance positions (Sussman et al., 2004) than a constant decline in MMN amplitude (Grimm \& Schröger, 2005; Timm et al., 2011; Weise et al., 2011; Yabe et al., 2001). Thus, other factors might have caused this effect, which becomes even more evident from the behavioral data showing lowest accuracy for the second deviance position (Sussman et al., 2004). 
the temporal window of integration anew. Thus, terminal parts of the time-variant sounds could be adequately represented and accessed by the deviance detection system, while this was not the case for time-invariant stimuli. Accordingly, these findings highlight the role of auditory transients in the trace formation process for sounds spanning more than a few hundred milliseconds and, thus, their functional relevance for higher cognitive processes (e.g., unimpaired discrimination of sequential sounds, information retrieval).

In another study we further highlighted the importance of transients for automatic trace formation. We tested the alternative explanation stating that the temporal constraint for time-invariant stimuli is due to a lack of varying spectral information over time rather than due the lack of transients (Weise et al., 2010). The underlying mechanism could be the decrease of neural activity caused by the adaptation of frequency specific neurons (Ulanovsky et al., 2004; Wark et al., 2007). We tested the 'lack of transient' hypothesis versus the 'lack of spectral variation' hypothesis by utilizing frequency glides that were characterized by a varying frequency spectrum over time, in terms of a continuous linear increase in frequency (Weise et al., 2010). Crucially, in one of the conditions we replaced the 300-450 ms interval of the frequency glides with a noise burst. Deviants differed from standards in duration. Without the noise burst as an additional auditory edge, the late deviance did not evoke MMN. This finding rules out the 'lack of spectral variation'-hypothesis, because despite the presence of a gradual rise in frequency - activating different neuronal populations and preventing adaptation - the temporal limitation in trace formation persisted. Hence, time-invariant sounds (Grimm et al., 2004; Näätänen et al., 2004) and frequency glides (Weise et al., 2010) underlie the same temporal constraint in forming auditory representations. Importantly, we found MMN to the 600-ms duration deviant when the frequency glide was segmented by a noise burst (Weise et al., 2010). This is in line with our hypothesis that transients initiate integration anew, thus playing a key role in automatic trace formation.

The significance of auditory transients (including sound onset) in trace formation is highlighted by their 'preferred' neural processing compared to that of time-invariant parts of the sound. To make this claim, we did not only analyze deviance-related activity but also activity related to sound onset as well as to the auditory transient occurring within the sound. It revealed that - similar to sound onset - the auditory edge (gap, noise burst) elicited prominent N1 and P2 potentials (e.g., Weise et al., 2007, 2010, 2012a). This fits to the findings showing that sound onset triggers more neuronal activity in the auditory nerve (Pickles, 1988) and increasingly in primary and non-primary auditory cortices (Harms et al., 2005) than the remainder of the time-invariant sound (Middlebrooks, 2005; Wang et al., 2005b). Moreover, transients and sound onsets play an essential role in auditory scene analysis in which they serve to segment the auditory input (Fishbach et al., 2001; Phillips et al., 2002; Winkler et al., 2009), which is for instance relevant to detect word boundaries (Sanders et al., 2002; Sanders \& Neville, 2003). 
In a further study we tested directly for a link between the sensory encoding of the transient, indexed by the elicitation of the P1-N1-P2 complex, and the trace formation, indexed via MMN (Weise et al., 2012a). In that study we took advantage of an asymmetry in the sensory encoding of physically identical but time-reversed transitions between segments of constant and gradually changing frequency. Previous research has shown a distinct N1-P2 to constant-to-glide transitions (cf. Arlinger et al., 1976; Clynes, 1969; Kohn et al., 1978; Maiste \& Picton, 1989; Noda et al., 1999), while a significant smaller transition-related response was observed for glide-to-constant transitions (Clynes, 1969; Kohn et al., 1978; Weise et al., 2012b, 2018). In separate blocks, we presented 1400-ms sounds with a centered constant-to-glide or glide-to-constant transition. Deviant sounds were shortened to $910 \mathrm{~ms}$. Crucially, we found larger transition-related N1-P2 potentials accompanied by larger deviance-related MMN/N1 ${ }^{6}$ amplitudes for sounds with constant-to-glide transition than for sounds with glide-to-constant transition. This outcome strongly supports the idea that the precise sensory encoding of transitions, as reflected by N1-P2, is a crucial trigger for the trace formation process.

Our findings (Weise et al., 2012a) might also help to some extent in resolving the apparently puzzling (though rare) observation of a temporal distance effect on MMN amplitude for deviances in time-variant sounds (e.g., Yabe et al., 2001, 2004)7 . For example, one of those studies used 170-ms sounds that consisted of five brief segments (each $\leq 36 \mathrm{~ms}$ including 4-ms rise/fall times), which occurred in close temporal succession (Yabe et al., 2001). Deviants differed from standards in that one of the segments, in particular segment two, three, or four, was replaced by a silent interval. MMN to the segment-omission decreased with increased temporal position of the deviance relative to sound onset. Thus, the auditory transition (i.e., the rising and falling ramps of each segment) was probably not effective enough to initiate integration anew. In line with this, the transitions did not elicit N1-P2. We like to emphasize that the amplitude modulations within the sound contribute to the perception of a 'wobble' even though these transitions receive no 'preferential' processing (i.e., absent N1-P2).

\footnotetext{
${ }^{6}$ The true size of MMN could not be estimated because N1, elicited by the offset of the deviant sound, could not be canceled out by subtracting the ERP to the long-lasting standard sound from the ERP to the shortened deviant sound. Therefore, both MMN and N1 contribute to the signal. However, it is implausible that the difference in MMN/N1 amplitudes between conditions originates from the offset-related potentials. The difference is much more likely to be due to a variation in the deviance-related MMN (cf. Weise et al., 2012a).

${ }^{7}$ Note that not every data set (e.g., Schröger et al., 1992) indicating a temporal distance effect on MMN amplitude necessarily reflects the temporal decay in sound representation. Schröger \& colleagues (1992), for example, found larger MMN for an early versus a late deviating tonal element of an eight-tone pattern of varying spectral content. This does, however, not necessarily reflect the decay in sound representation over time. More likely, this pattern of results reflects the impaired discrimination performance between standard and deviant sounds due to masking. This notion is supported by the behavioral data collected in an active discrimination task subsequent to the passive EEG recording. These data reveal also an impaired discrimination performance for a late (15\%) versus an early $(77 \%)$ deviating segment within the sound pattern. Such a dramatic impairment in the behavioral performance was not reported by studies focusing on the temporal decay in sound representation (Hoonhorst et al., 2012; Timm et al., 2011; Yabe et al., 2004).
} 
However, it is interesting that not all but only certain types of auditory transitions trigger a new integration process (Weise et al., 2010, 2012a; Yabe et al., 2001, 2004). This can be seen as a beneficial property of the auditory system. When sequential information is more likely to belong to the same sound, the most efficient way to form an auditory representation is to build as few perceptual chunks as needed.

To sum up, in addition to the onset, time-varying characteristics within long lasting sounds play a crucial role for automatic trace formation. Of relevance are especially those acoustic transitions that receive a precise sensory encoding or preferred processing, indicated by the elicitation of N1-P2. Those transients serve as triggers to initiate temporal integration anew and, as a consequence, each of those acoustic edges initiates the emergence of another perceptual chunk. Thus, each part of the sound - whether occurring early or late following sound onset - can contribute to the auditory representation.

\section{The role of neural oscillations for the formation of auditory representations}

In the previous chapter, we learned from MMN research that segmenting time-variant sounds in perceptual chunks - mediated by the temporal window of integration - aids the representation of long lasting sounds. A closely related concept is known from research on neural oscillations. As we will argue below it seems reasonable to consider certain neural oscillations as possible physiological underpinnings of such a segmentation process. Before elaborating on that, we first introduce neural oscillations to the naive reader.

From a broader perspective, neural oscillations have been observed widespread across the brain (Buzsáki 2004; Buzsáki et al. 2013; Singer 2018), including auditory cortex (Lakatos et al., 2005). They hold a characteristic profile within the different cortical areas (Keitel \& Gross, 2016; Lubinus et al., 2021) and are present even without external stimulation (Herrmann et al., 2016). Physiologically they are thought to reflect rhythmic fluctuations in neural excitability cycles and most likely emerge from neurons acting as self-sustained oscillators or synchronized neuron populations (Llinas, 1988; Pikovsky et al., 2001).

Of particular relevance for our framework are data that originate from studies focusing on the role of neural oscillations in the segmentation of time-variant sounds (Lakatos et al., 2005; Panzeri et al., 2010) including speech (Giraud \& Poeppel, 2012; Ding \& Simon, 2014; Kösem et al., 2018) or music (Doelling \& Poeppel, 2015; Harding et al., 2019). The notion of a close correspondence between neural oscillations and the temporal segmentation of an input stream allowing for the subsequent decoding of sensory information has resulted in extensive research (Ding et al., 2016; Doelling et al., 2014; Ghitza et al., 2013; Giraud \& Poeppel, 2012; Gross et al., 2013; Henin et al., 2021; Henry \& Obleser, 2012; Luo \& Poeppel, 2007; Luo et al., 2013; Rimmele et al., 2015; Teng et al., 2018). In fact, it has been shown that the theta and delta oscillations can track the dynamics of speech at corresponding timescales (Giraud \& Poeppel, 2012). In particular, it has been proposed that theta $(4-8 \mathrm{~Hz})$ oscillations segment the acoustic input at the syllabic level - with the most prominent acoustic edges at this time scale (Ding et al., 2017; Varnet et al., 2017). Further, low gamma oscillations $(\gtrsim 30 \mathrm{~Hz}$ ) can be coupled with theta and have been linked to phonemic 
processing (Giraud \& Poeppel, 2012; Hyafil et al., 2015). More recently, a role of delta oscillations (0.5-2 $\mathrm{Hz}$ ) in segmenting the input stream at the phrasal time scale has been discussed (Bonhage et al., 2017; Boucher et al., 2019; Ding et al., 2016; Keitel et al., 2018; Meyer et al., 2017; Rimmele et al., 2021; Stehwien \& Meyer, 2021).

Of particular interest for the current framework is the finding that theta-band neural oscillations in auditory cortex are involved in speech segmentation at the syllabic scale (Giraud \& Poeppel, 2012; Ghitza, 2011, 2013; Gross et al., 2013; Haegens \& Zion Golumbic, 2018; Hovsepyan et al., 2020; Keitel et al., 2016; Luo \& Poeppel, 2007; Meyer et al., 2020; Rimmele et al., 2018). Given that the cycle of theta-band oscillations (4-8 Hz) corresponds approximately to the syllable duration, oscillations seem to enable speech segmentation by constituting a 'temporal integration window' at the syllabic scale (Poeppel, 2003; Giraud \& Poeppel, 2012). This may also explain why intelligibility drops for artificially compressed speech at fast rates beyond the theta 'temporal integration window' while it can be restored when sufficient decoding time is provided by adding silent gaps (Doelling et al., 2014). From a more mechanistic point of view, acoustic edges related to the acoustic onset of syllables, or the amplitude peaks related to vocalic nuclei reset the phase of the auditory theta oscillatory activity (Doelling et al., 2014; Oganian \& Chang, 2019; Park et al., 2015; see also: Aubanel et al., 2016). The phase-reset initiates the speech segmentation by aligning the neural excitability in the auditory cortex to the acoustic energy fluctuations of the speech signal at the syllabic scale (termed 'entrainment').

Remarkably, both the 'temporal integration window' suggested by research on neural oscillations and the temporal window of integration - the putative process engaged in forming auditory representations - share various commonalities such as similar temporal characteristics. Moreover, each of them appear to be engaged in segmenting the acoustic input into meaningful chunks / perceptual entities based on acoustic edges. Also, similar to the formation of auditory representations, neural oscillations track the signal when the acoustic input is not attended to (Haegens \& Zion Golumbic, 2018; Rimmele et al., 2015; Zion Golumbic et al., 2013). It has, for example, been shown in the well known cocktail party situation that unattended speech is coded at the early auditory cortex level (Zion Golumbic et al., 2013). So far, research did not focus on investigating whether auditory theta oscillations may relate to auditory trace formation for long lasting sounds. However, there are studies showing that for ambiguous phonemes the neural oscillatory characteristics (phase and rate) affect the identity of the perceived syllable (Kösem et al., 2018; Ten Oever \& Sack, 2015). This may point in the direction that auditory theta oscillations play a role in auditory trace formation, possibly by segmenting the auditory input.

The findings reviewed above pose several questions concerning whether or not the temporal window of integration and the oscillatory 'temporal integration window' reflect similar processes (see also: Rimmele et al., 2015). Related to that are the questions whether neural oscillatory activity plays a role in auditory 
trace formation and whether phase-resetting to acoustic edges is crucial for initiating a temporal window of integration.

To sum up, the neural oscillatory approach studying speech segmentation uncovered a 'temporal integration window' that shows parallels in its characteristics and functions to the temporal window of integration. Both span a few hundred of milliseconds, operate without the need to attend the sounds and have the putative role to segment the acoustic input stream. Future research needs to further address how these processes relate to each other. One plausible notion is that neural theta oscillations form the physiological underpinning of the segmentation process mediated via the temporal window of integration.

\section{Updated model for the formation of auditory representations}

As became evident from the literature reviewed above, the temporal window of integration seems to play a crucial role in the formation of auditory representations. It binds auditory information over a restricted period of time into a perceptual entity. For fine-grained auditory sensory, non-categorized information the upper limit of the temporal window of integration seems to be between $160 \mathrm{~ms}$ and $350 \mathrm{~ms}$. The varying time range that the integration window covers emphasizes that the integration process is not static. Rather, it depends on the characteristics within the auditory input across different time points. That notion fits with the assumption of a 'spectrotemporal window' of integration which binds events based on their temporal and spectral separation (Shinozaki et al., 2003). Accordingly, when the spectral or temporal difference between adjacent elements is large, the integration period is rather short. When tones are continuous and time-invariant the temporal window of integration can be of longer duration (Grimm \& Schröger, 2005; Grimm et al., 2006; Hoonhorst et al., 2012). These findings promote the view that the neural mechanisms underlying this sensory integration function involve an overlap in neural activation within a network of neurons. Accordingly, the time span of the temporal window of integration is defined by the decay time of neural activation and the spatial proximity of neural populations along the tonotopic axis.

The long phase of auditory memory comes into play when the content of the resulting temporal unit has to be kept in memory so that it remains retrievable. While the temporal window of integration / the short phase of ASM provides the duration of the detailed content that is stored as a sound representation, the long phase of auditory memory defines the duration for how long the sound representation can be stored. This duration may last up to several seconds. Behavioral research suggests a duration of up to 30 secs, though the sound representation may be prone to memory decay in the first few seconds after the sound occurred (e.g., Cowan, 1988). Also MMN research shows similar time estimates for how long an auditory representation can be stored. A common finding is that a silent interval exceeding 10 to $12 \mathrm{~s}$ between the last regular sound and the upcoming deviant prevents MMN elicitation (Sams et al., 1993; Winkler et al., 2001). In such situations a single sound - having the role of a 'reminder' - can 'reactivate' the regularity representation so that MMN is re-gained to the upcoming deviant. This reactivation phenomenon can even be observed when the reminder and the preceding regular sound are separated by $30 \mathrm{~s}$ (Winkler et al., 2002; 
for review, see Winkler \& Cowan, 2005). Even random auditory signals can be memorized for several seconds, as has been shown in studies using periodic noise (e.g., Kaernbach, 2004): when a noise signal is repeated in periodic cycles, with little training listeners can detect the periodicity for cycle lengths of up to 10 or even 20 seconds. Further it has been shown that not the exact signal characteristics of the whole cycle length are memorized, but rather selected portions generally not extending over much more than $100 \mathrm{~ms}$ (Kaernbach, 1993). The spectro-temporal structure of these portions is perceptually enhanced and their recurrence detected. Whereas some authors argue that phase information is irrelevant for the perception of periodic noise (Warren \& Wrightson, 1981; Patterson et al., 1983), others argue it is a crucial detail that is stored and memorized (Limbert, 1984; Kaernbach, 1993). A more recent study comes to similar conclusions, assuming that sounds that are texture-like and of longer duration (e.g., rain, wind etc.) are stored mainly according to their time-averaged statistics while access to detailed temporal structure might only be retained for certain portions (McDermott et al., 2013). That is, short detailed units of spectro-temporal representations can be held and integrated with later information - a function that is crucial for representing long lasting sound events

The bottleneck in the formation of auditory representations seems to be linked to the capacity of the temporal window of integration (Grimm \& Schröger, 2005; Timm et al., 2011; Weise et al., 2010; Yabe et al., 2001). If only sound onset and no further auditory edge is available within the sound (despite sound offset), auditory representations of late sound parts cannot be established, and thus, cannot be used / accessed by higher cognitive functions (e.g., sound discrimination, recall).

Our updated model on the formation of auditory representations suggests a putative relevant mechanism that allows for the representation of the complete stimulus information and its access by higher cognitive functions (e.g., information retrieval). It proposes that the sensory integration window needs to be initiated anew via certain types of auditory edges inherent to the sound (Weise et al., 2010, 2012a). This may result in temporally adjacent integration windows which segment the sensory information into auditory representations. At the neural level this may be achieved by the activity of 'overlapping' neural populations (coding for sensory information of similar spectral content) as has been suggested in the context of auditory streaming (Fishman et al., 2001; for a review, see Bidet-Caulet \& Bertrand, 2009). To allow the formation of temporally large-scale representations such as sound patterns or words, the auditory representations can, thus, be unitized into one 'concatenated' auditory representation at a higher hierarchical level. 
SOA

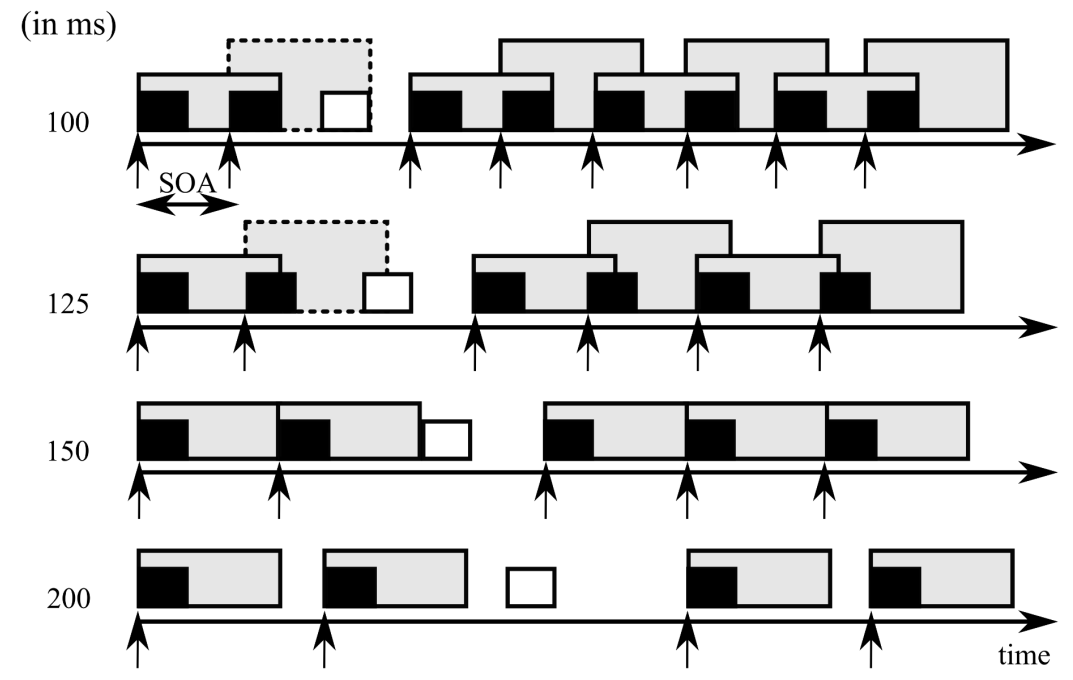

Legend
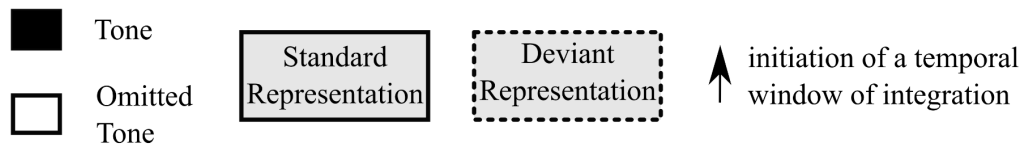

Figure 1: A schema illustrating the impact of the length of onset asynchrony (SOA) on the formation of an auditory representation. Black bars represent tones. Empty bars represent omitted tones. Each arrow indicates the initiation of the temporal window of integration. Short SOAs $(<150 \mathrm{~ms})$ result in temporally-adjacent or even overlapping integration windows that lead to the formation of standard representations each comprising two tones and a gap (grey bar with solid black frame) or, in case of an omitted tone a deviant representation comprising only a single tone and a longer gap (grey bar with dotted black frame). Longer SOAs result in the formation of (standard) representations comprising only a single tone and a long gap. (adapted from Yabe et al., 1997)

The notion of temporally adjacent integration windows is not completely new and receives electrophysiological support from studies utilizing the tone-omission paradigm (Yabe et al., 1997, 1998). The authors found MMN in response to an irregular omission of one of the regularly presented tones only for $(<170 \mathrm{~ms})$ short onset-to-onset intervals. From these data the authors speculated that each upcoming tone in the sequence initiates a new temporal window of integration. Crucially, in case of a $(<170 \mathrm{~ms})$ short-onset-to-onset interval between two adjacent sounds, the second tone entered the integration process initiated by the onset of the first tone, thereby allowing the formation of a concatenated (standard) auditory representation comprising two single tonal events with a gap (Figure 1). In case of an omitted tone, the (deviant) auditory representation comprised only one tone, thus evoking the deviance-related MMN. Importantly, this assumption is based on the existence of temporally adjacent integration processes (Figure 1) as otherwise (i.e., when the second of two integrated tones does not initiate a new integration process) omissions were not detectable (as only representations comprising two tones with a gap were established). 

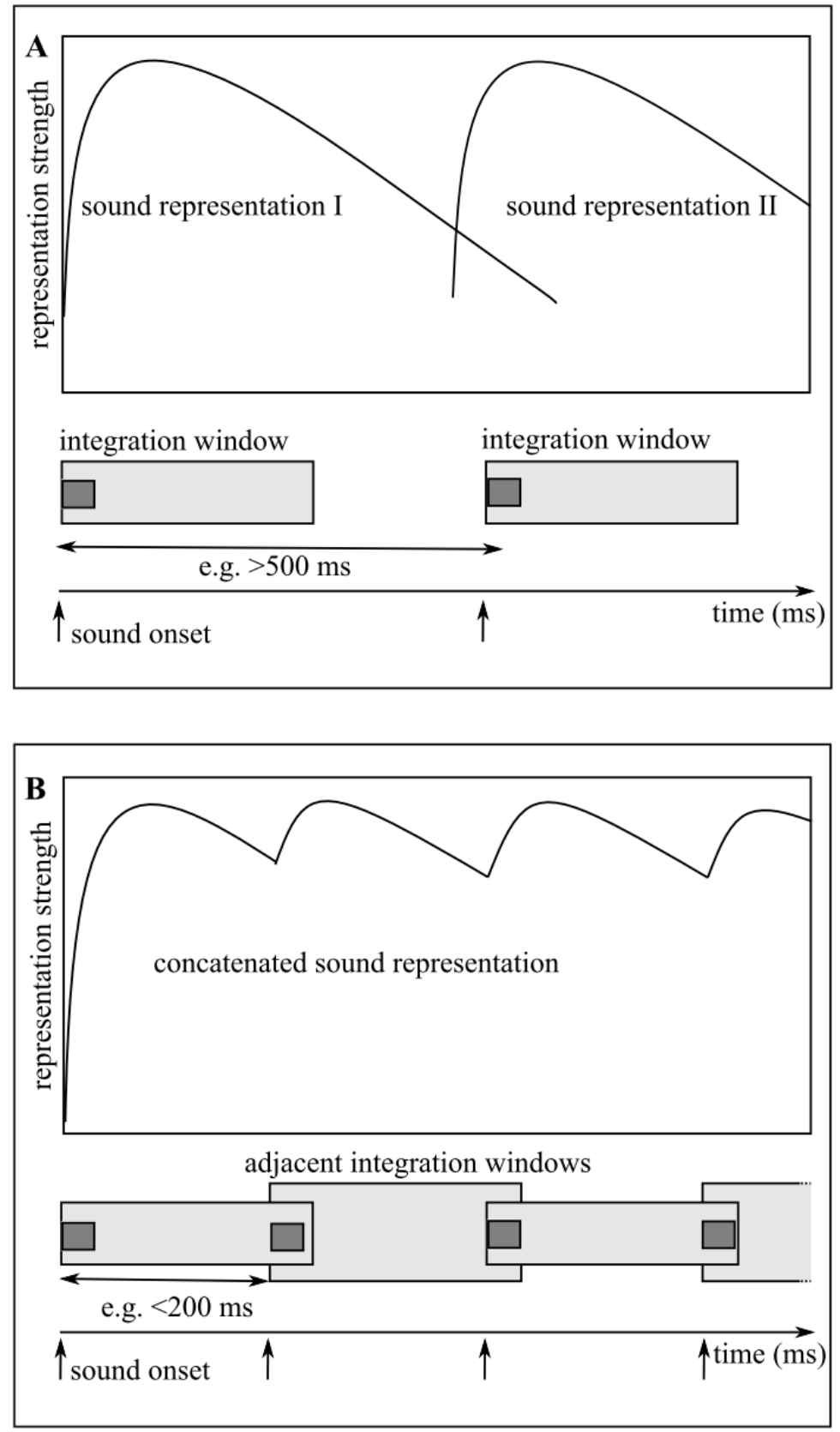

Figure 2: Schema illustrating the formation of discrete sound representations (A) and a long concatenated sound representation (B). (A) Each auditory edge (here: sound onset) initiates a temporal window of integration resulting in several brief, discrete sound representations. (B) If those auditory edges occur in close temporal succession one long, concatenated sound representation is formed due to adjacent temporal windows of integration.

Temporally adjacent integration windows may not solely result in discrete brief sound representations (Figure 1, Figure 2A) but even in a concatenated longer auditory representation (Figure 2B). This can be inferred from the outcome of studies utilizing pattern stimuli (Atienza et al., 2003; Sussman \& Gumenyuk, 
2005; van Zuijen et al., 2004). In one of these studies (Sussman \& Gumenyuk, 2005), for instance, MMN was measured to a high-frequency tone (B) that occurred in a sequence of low-frequency tones (A-A-A-A; where '-' represents the onset-to-onset interval) at every fifth position (i.e., A-A-A-A-B). In different conditions the onset-to-onset interval was either 200, 400, 600, or $800 \mathrm{~ms}$. MMN was found in all conditions except in the one, in which the onset-to-onset interval was $200 \mathrm{~ms}$. This suggests that for the 200-ms onset-to-onset interval condition the whole pattern (A-A-A-A-B) was stored as (unitary) $>800$-ms auditory representation, which may be explained by temporally-adjacent integration windows. Contrary, when the onset-to-onset interval between adjacent tones was $400 \mathrm{~ms}$ and longer, discrete auditory representations were built for $\mathrm{A}$ and $\mathrm{B}$ tones, respectively. The reason for this is probably that the integration windows, initiated by each individual tone (A or B), were temporally too far apart and thus failed to bind the shorter perceptual units into a longer auditory representation. Similar conclusions can be drawn, for instance, from the outcome of a deviance-position approach (van Zuijen et al., 2004), in which MMN was measured to a rare occurring fifth tonal element within an otherwise regularly occurring four-tone pattern. Thereby, the tonal elements were separated by an onset-to-onset interval of $187.5 \mathrm{~ms}$. Within each sound pattern, tonal elements shared the same frequency, whereas across sound patterns the frequency values varied. The elicitation of MMN to the 5th tonal element, occurring far beyond $350 \mathrm{~ms}$ following pattern onset, reflected the detailed auditory representation for such pattern stimuli.

Anyway, at this point we would like to stress again the fact that our updated model focuses on one particular mechanism only which aids in forming full-fledged auditory representations. It does by no means provide a complete picture. That is, we do not claim that the formation of auditory representations may be mediated only via adjacent temporal windows of integration. Research suggests that there exist indeed several other mechanisms aiding in building such temporally large-scale auditory representations. For example, MMN has been found to late deviances within pattern stimuli even when the silent interval between 400-ms long lasting tonal elements of a pattern are separated by 500 -ms and more (Herholz et al., 2009; see also Salisbury, 2012; Weise et al., 2014 for further empirical support). Those findings might rather be explained by a higher-order/ categorical binding mechanism. We have argued that the processing underlying the establishment of representations for long lasting sounds happens rather automatically. In fact, these representations provide the informational basis for the conscious perception / processing of long lasting sounds rather than being the outcome of such attentional / intentional processing. Nevertheless, some findings point to the notion that directing attention to the sound input can help to prolong the temporal window of integration (Grimm et. al., 2004; Grimm \& Schröger, 2005). As attention has an impact on many levels along the auditory pathway (Fritz et al., 2007; Kaya \& Elhilali, 2017), it seems very likely that attention can to some extent modulate the processing involved in the establishment of representations for long lasting sounds.

Overall, the memory representations discussed in this paper can be localized at the transition from a mere sensory to a more cognitive processing level. This fits to conceptualisations according to which the mind / 
brain hosts a hierarchy of temporal receptive windows (Lerner et al., 2014) or intrinsic neural timescales (Golesorkhi et al., 2021).

To sum up, our updated model proposes the notion that the auditory representation of a long lasting sound relies (partly) on adjacent temporal windows of integration. These windows are initiated via auditory edges inherent to the sound and they segment the sensory information into temporal chunks with its content corresponding to the sound percept. This can be seen as one of possibly many mechanisms that are involved in auditory trace formation.

\section{Conclusion, challenges, and future directions}

What has become evident from the studies reviewed above is that the auditory representation relies on certain temporal dynamics - or so called auditory edges (e.g., frequency- and/or amplitude modulations) within the sound (Atienza et al., 2003; Grimm et al., 2006; Näätänen et al., 2004; Partanen et al. 2011; Pulvermüller et al., 2001; Weise et al., 2007; 2010, 2011, 2012a; Winkler \& Schröger, 1995; van Zuijen et al., 2004). These edges are crucial determinants to trigger adjacent temporal windows of integration (Yabe et al, 1997) and thus guarantee an adequate full-fledged auditory representation of a long lasting time-variant sound. The putative functional significance of the temporal window of integration is to segment the sensory information into shorter mental chunks. That is, information of a long stimulus is segmented into manageable units, each of which can, thus, be represented as a perceptual entity. This may contribute to the fact that we can recall spoken language even without attentively listening to it.

Despite the progress that has been achieved in understanding aspects of how auditory representations evolve; several questions still remain open on that topic and will require more research. It would be intriguing to better characterize the types of auditory changes, which aid sound representation / or at which time scales the sensory information of acoustic properties is segmented into perceptual entities. This is especially relevant as in more natural sounds like speech time-varying characteristics occur at various time scales (Ahissar et al., 2001; Rosen, 1992).

Related to that is the question whether segmentation at different time scales is achieved by one 'superior' mechanism - neural theta oscillation may be one key candidate - or whether distinct processes are at play (e.g., neural oscillations at different frequencies for segmentation/integration at different levels along the processing hierarchy as suggested by Poeppel, 2003). This endeavor may require complementary methods to the ERP approach such as, for instance, analyzing neuronal oscillations or brain waves using various analysis techniques. Additionally, to the information retrieved from the ERP analysis such an approach allows extracting information about different frequency bands and the phase of rhythmic brain activity, which has been linked to processes segmenting the auditory input (Giraud \& Poeppel, 2012; Park et al., 
2015). Thus, this seems a promising complementary approach to the ERP/MMN method: the former focusing on mechanisms indexing segmentation, the latter tracking auditory representation.

The research discussed in this review article prompts new ideas. For example, it would be interesting to study whether perceptual learning of auditory transients also has functional consequences for the formation of auditory representations. If we consider, for instance, the importance of segmentation cues in the context of speech (Cunillera et al., 2008; Peña et al., 2002; Sanders \& Neville, 2003; Sanders et al., 2009), it is evident that learning a new language benefits from learning to identify word boundaries (Sanders \& Neville, 2003; Sanders et al., 2009). From that perspective, it might be crucial to know whether the segmentation of long lasting sounds due to perceptually learned transients also enables the adequate auditory representation including late stimulus information. This research would add to the controversy of communalities and differences between processing non-speech and speech sounds (Belin et al., 2000; Overrath et al., 2015).

Another question concerns the variable time span of the temporal window of integration ranging from tens of milliseconds (e.g., Shinozaki et al., 2003) up to about $350 \mathrm{~ms}$ (Grimm et al., 2006). Related to that, the idea of adjacent temporal windows of integration seems straightforward. However, there are several data sets, which point to further - rather higher-order / categorical - mechanisms at play in the formation of auditory representations (e.g., Grimm \& Schröger, 2005; Herholz et al., 2011; Salisbury, 2012; Weise et al., 2014). It would be of interest to systematically study the relation of first-order vs. higher-order mechanisms enabling representations of long sounds.

\section{Acknowledgements}

This work was supported by the German Research Foundation (Schr375/19-2 and Reinhart-Koselleck Project Schr375/20-1: AW, ES; WE6085/2-1: AW), the DAAD (Project ID: 57185798: AW; Project ID 0811948: SG), and by the Spanish ministry of Science and Innovation (Acciones Integradas grant HD 2008-10: SG).

\section{Author contributions}

Annekathrin Weise: Writing- Original draft preparation, Reviewing and Editing. Sabine Grimm: WritingOriginal draft preparation, Reviewing and Editing. Johanna Rimmele: Writing- Original draft preparation, Reviewing and Editing. Erich Schröger: Writing- Reviewing and Editing. 


\section{References}

Ahissar, E., Nagarajan, S., Ahissar, M., Protopapas, A., Mahncke, H., \& Merzenich, M. M. (2001). Speech comprehension is correlated with temporal response patterns recorded from auditory cortex. Proceedings of the National Academy of Sciences of the United States of America, 98(23), 13367-13372. https://doi.org/10.1073/pnas.201400998

Alain, C. (2007). Breaking the wave: Effects of attention and learning on concurrent sound perception. Hearing Research, 229(1-2), 225-236. https://doi.org/10.1016/j.heares.2007.01.011.

Alho, K. (1995). Cerebral generators of mismatch negativity (MMN) and its magnetic counterpart (MMNm) elicited by sound changes. Ear and Hearing, 16(1), 38-51. https://doi.org/10.1097/00003446-199502000-00004

Althen, H., Grimm, S., \& Escera, C. (2011). Fast detection of unexpected sound intensity decrements as revealed by human evoked potentials. PLoS ONE, 6(12), e28522. https://doi.org/10.1371/journal.pone.0028522

Althen, H., Grimm, S., \& Escera, C. (2013). Simple and complex acoustic regularities are encoded at different levels of the auditory hierarchy. The European Journal of Neuroscience. https://doi.org/10.1111/ejn.12346

Amenedo, E., \& Escera, C. (2000). The accuracy of sound duration representation in the human brain determines the accuracy of behavioural perception. The European Journal of Neuroscience, 12(7), 2570-2574. https://doi.org/10.1046/j.1460-9568.2000.00114.x

Arlinger, S. D., Jerlvall, L. B., Ahrén, T., \& Holmgren, E. C. (1976). Slow evoked cortical responses to linear frequency ramps of a continuous pure tone. Acta Physiologica Scandinavica, 98(4), 412-424. https://doi.org/10.1111/j.1748-1716.1976.tb10330.x

Atienza, M., Cantero, J. L., Grau, C., Gomez, C., Dominguez-Marin, E., \& Escera, C. (2003). Effects of temporal encoding on auditory object formation: a mismatch negativity study. Brain Research. Cognitive Brain Research, 16(3), 359-371. https://doi.org/10.1016/s0926-6410(02)00304-x

Atkinson, R. C., \& Shiffrin, R. M. (1968). Human memory: A proposed system and its control processes. In K. W. Spence \& J. T. Spence (Eds.), The psychology of learning and motivation: Advances in research and theory (pp. 89-195). Academic Press. 
Aubanel, V., Davis, C., \& Kim, J. (2016). Exploring the role of brain oscillations in speech perception in noise: Intelligibility of isochronously retimed speech. Frontiers in Human Neuroscience, 10, 430. https://doi.org/10.3389/fnhum.2016.00430

Baldeweg, T. (2006). Repetition effects to sounds: evidence for predictive coding in the auditory system. Trends in Cognitive Sciences, 10(3), 93-94. https://doi.org/10.1016/i.tics.2006.01.010

Barry, J. G., Hardiman, M. J., \& Bishop, D. V. M. (2009). Mismatch response to polysyllabic nonwords: A neurophysiological signature of language learning capacity. PLOS ONE, 4(7), e6270. https://doi.org/10.1371/journal.pone.0006270

Belin, P., Zatorre, R. J., Lafaille, P., Ahad, P., \& Pike, B. (2000). Voice-selective areas in human auditory cortex. Nature, 403(6767), 309-312. https://doi.org/10.1038/35002078

Bendixen, A., Scharinger, M., Strauß, A., \& Obleser, J. (2014). Prediction in the service of comprehension: Modulated early brain responses to omitted speech segments. Cortex, 53, 9-26. https://doi.org/10.1016/j.cortex.2014.01.001

Bendixen, A., Schröger, E., \& Winkler, I. (2009). I heard that coming: event-related potential evidence for stimulus-driven prediction in the auditory system. The Journal of Neuroscience, 29(26), 8447-8451. https://doi.org/10.1523/JNEUROSCI.1493-09.2009

Bidet-Caulet, A., \& Bertrand, O. (2009). Neurophysiological mechanisms involved in auditory perceptual organization. Frontiers in Neuroscience, 3(2), 182-191. https://doi.org/10.3389/neuro.01.025.2009

Bonhage, C. E., Meyer, L., Gruber, T., Friederici, A. D., \& Mueller, J. L. (2017). Oscillatory EEG dynamics underlying automatic chunking during sentence processing. NeuroImage, 152, 647-657. https://doi.org/10.1016/j.neuroimage.2017.03.018

Boucher, V. J., Gilbert, A. C., \& Jemel, B. (2019). The role of low-frequency neural oscillations in speech processing: Revisiting delta entrainment. Journal of Cognitive Neuroscience, 31(8), 1205-1215. https://doi.org/10.1162/jocn a 01410

Bregman, A. S. (1994). The Auditory Scene. In Auditory Scene Analysis (pp. 1-45). MIT Press. Broadbent, D. E. (1954). The role of auditory localization in attention and memory span. Journal of Experimental Psychology, 47(3), 191-196. https://doi.org/10.1037/h0054182 
Broadbent, D. E. (1958). Chapter 9-Immediate memory and the shifting of attention. In D. E. Broadbent (Ed.), Perception and Communication (pp. 210-243). Pergamon. https://doi.org/10.1016/B978-1-4832-0079-8.50011-6

Buzsáki, G. (2004). Large-scale recording of neuronal ensembles. Nature Neuroscience, 7(5), 5. $\underline{\text { https://doi.org/10.1038/nn1233 }}$

Buzsáki, G., Logothetis, N., \& Singer, W. (2013). Scaling brain size, keeping timing: Evolutionary preservation of brain rhythms. Neuron, 80(3), 751-764.

\section{https://doi.org/10.1016/j.neuron.2013.10.002}

Clynes, M. (1969). Dynamics of vertex evoked potentials: The R-M brain function. In E. Donchin \& L. B. Lindsley (Eds.), Average evoked potentials: Methods, results, evaluation (pp. 363-374). NASA.

Colin, C., Hoonhorst, I., Markessis, E., Radeau, M., de Tourtchaninoff, M., Foucher, A., Collet, G., \& Deltenre, P. (2009). Mismatch negativity (MMN) evoked by sound duration contrasts: An unexpected major effect of deviance direction on amplitudes. Clinical Neurophysiology, 120(1), 51-59. https://doi.org/10.1016/j.clinph.2008.10.002

Cornella, M., Leung, S., Grimm, S., \& Escera, C. (2012). Detection of simple and pattern regularity violations occurs at different levels of the auditory hierarchy. PloS One, 7(8), e43604. https://doi.org/10.1371/journal.pone.0043604

Cowan, N. (1984). On short and long auditory stores. Psychological Bulletin, 96(2), 341-370.

Cowan, N. (1988). Evolving conceptions of memory storage, selective attention, and their mutual constraints within the human information-processing system. Psychological Bulletin, 104(2), 163-191. https://doi.org/10.1037/0033-2909.104.2.163

Cowan, N. (2005). Working Memory Capacity. Psychology Press. https://doi.org/10.4324/9780203342398

Cowan, N. (2008). What are the differences between long-term, short-term, and working memory? Progress in Brain Research, 169, 323-338. https://doi.org/10.1016/S0079-6123(07)00020-9

Crowder, R., \& Morton, J. (1969). Precategorical acoustic storage (PAS). Attention, Perception, \& Psychophysics, 5(6), 365-373. https://doi.org/10.3758/BF03210660 
Cunillera, T., Gomila, A., \& Rodríguez-Fornells, A. (2008). Beneficial effects of word final stress in segmenting a new language: Evidence from ERPs. BMC Neuroscience, 9, 23. https://doi.org/10.1186/1471-2202-9-23

Demany, L., \& Semal, C. (2007). The role of memory in auditory perception. In W. A. Yost, A. N. Popper, \& R. R. Fay (Eds.), Auditory Perception of Sound Sources. Springer US; 77-113.

Deouell, L. Y. (2007). The frontal generator of the mismatch negativity revisited. Journal of Psychophysiology, 21(3-4), 188-203. https://doi.org/10.1027/0269-8803.21.34.188

Dimitrijevic, A., Lolli, B., Michalewski, H. J., Pratt, H., Zeng, F.-G., \& Starr, A. (2009). Intensity changes in a continuous tone: auditory cortical potentials comparison with frequency changes. Clinical Neurophysiology, 120(2), 374-383. https://doi.org/10.1016/i.clinph.2008.11.009

Dimitrijevic, A., Michalewski, H. J., Zeng, F.-G., Pratt, H., \& Starr, A. (2008). Frequency changes in a continuous tone: Auditory cortical potentials. Clinical Neurophysiology, 119(9), 2111-2124. https://doi.org/10.1016/j.clinph.2008.06.002

Ding, N., Melloni, L., Zhang, H., Tian, X., \& Poeppel, D. (2016). Cortical tracking of hierarchical linguistic structures in connected speech. Nature Neuroscience, 19(1), 158-164. https://doi.org/10.1038/nn.4186

Ding, N., Patel, A. D., Chen, L., Butler, H., Luo, C., \& Poeppel, D. (2017). Temporal modulations in speech and music. Neuroscience \& Biobehavioral Reviews, 81, 181-187. https://doi.org/10.1016/j.neubiorev.2017.02.011

Ding, N., \& Simon, J. Z. (2014). Cortical entrainment to continuous speech: functional roles and interpretations. Frontiers in Human Neuroscience, 8. https://doi.org/10.3389/fnhum.2014.00311

Doelling, K. B., Arnal, L. H., Ghitza, O., \& Poeppel, D. (2014). Acoustic landmarks drive delta-theta oscillations to enable speech comprehension by facilitating perceptual parsing. NeuroImage, 85 , Part 2, 761-768. https://doi.org/10.1016/j.neuroimage.2013.06.035

Doelling, K. B., \& Poeppel, D. (2015). Cortical entrainment to music and its modulation by expertise. Proceedings of the National Academy of Sciences, 112(45), E6233-E6242. https://doi.org/10.1073/pnas.1508431112 
Efron, R. (1970). The relationship between the duration of a stimulus and the duration of a perception. Neuropsychologia, 8(1), 37-55. https://doi.org/10.1016/0028-3932(70)90024-2

Eggermont, J. J. (2001). Between sound and perception: reviewing the search for a neural code. Hearing Research, 157(1-2), 1-42. https://doi.org/10.1016/s0378-5955(01)00259-3

Escera, C., Alho, K., Schröger, E., \& Winkler, I. (2000). Involuntary attention and distractibility as evaluated with event-related brain potentials. Audiology and Neuro-Otology, 5(3-4), 151-166. http://dx.doi.org/10.1159/000013877

Fishbach, A., Nelken, I., \& Yeshurun, Y. (2001). Auditory edge detection: A neural model for physiological and psychoacoustical responses to amplitude transients. Journal of Neurophysiology, 85(6), 2303-2323. https://doi.org/10.1152/in.2001.85.6.2303

Fishman, Y. I., Reser, D. H., Arezzo, J. C., \& Steinschneider, M. (2001). Neural correlates of auditory stream segregation in primary auditory cortex of the awake monkey. Hearing Research, 151(1-2), 167-187. https://doi.org/10.1016/s0378-5955(00)00224-0

Fitzgerald, K., \& Todd, J. (2020). Making sense of Mismatch Negativity. Frontiers in Psychiatry, 11. https://www.frontiersin.org/articles/10.3389/fpsyt.2020.00468

Ford, J. M., Roth, W. T., \& Kopell, B. S. (1976). Auditory Evoked Potentials to Unpredictable Shifts in Pitch. Psychophysiology, 13(1), 32-39. https://doi.org/10.1111/j.1469-8986.1976.tb033333.x

Fritz, J. B., Elhilali, M., David, S. V., \& Shamma, S. A. (2007). Auditory attention—Focusing the searchlight on sound. Current Opinion in Neurobiology, 17, 437-455. https://doi.org/10.1016/i.conb.2007.07.011

Ghitza, O. (2011). Linking speech perception and neurophysiology: speech decoding guided by cascaded oscillators locked to the input rhythm. Frontiers in Psychology, 2, 130. https://doi.org/10.3389/fpsyg.2011.00130

Ghitza, O. (2013). The theta-syllable: a unit of speech information defined by cortical function. Frontiers in Psychology, 4, 138. https://doi.org/10.3389/fpsyg.2013.00138

Ghitza, O., Giraud, A.-L., \& Poeppel, D. (2013). Neuronal oscillations and speech perception: Critical-band temporal envelopes are the essence. Frontiers in Human Neuroscience, 6, 340. https://doi.org/10.3389/fnhum.2012.00340 
Giraud, A.-L., \& Poeppel, D. (2012). Cortical oscillations and speech processing: emerging computational principles and operations. Nature Neuroscience, 15(4), 511-517. https://doi.org/10.1038/nn.3063

Golesorkhi, M., Gomez-Pilar, J., Zilio, F., Berberian, N., Wolff, A., Yagoub, M. C. E., \& Northoff, G. (2021). The brain and its time: Intrinsic neural timescales are key for input processing. Communications Biology, 4(1), 1. https://doi.org/10.1038/s42003-021-02483-6

Greenberg, S., \& Arai, T. (2001). The relation between speech intelligibility and the complex modulation spectrum. INTERSPEECH.

Grimm, S., Escera, C., Slabu, L., \& Costa-Faidella, J. (2011). Electrophysiological evidence for the hierarchical organization of auditory change detection in the human brain. Psychophysiology, 48(3), 377-384. https://doi.org/10.1111/j.1469-8986.2010.01073.x

Grimm, S., Roeber, U., Trujillo-Barreto, N. J., \& Schröger, E. (2006). Mechanisms for detecting auditory temporal and spectral deviations operate over similar time windows but are divided differently between the two hemispheres. NeuroImage, 32(1), 275-282.

https://doi.org/10.1016/j.neuroimage.2006.03.032

Grimm, S., \& Schröger, E. (2005). Pre-attentive and attentive processing of temporal and frequency characteristics within long sounds. Brain Research. Cognitive Brain Research, 25(3), 711-721. https://doi.org/10.1016/j.cogbrainres.2005.09.003

Grimm, S., \& Schröger, E. (2007). The processing of frequency deviations within sounds: evidence for the predictive nature of the Mismatch Negativity (MMN) system. Restorative Neurology and Neuroscience, 25(3-4), 241-249.

Grimm, S., Widmann, A., \& Schröger, E. (2004). Differential processing of duration changes within short and long sounds in humans. Neuroscience Letters, 356(2), 83-86. https://doi.org/10.1016/j.neulet.2003.11.035

Gross, J., Hoogenboom, N., Thut, G., Schyns, P., Panzeri, S., Belin, P., \& Garrod, S. (2013). Speech rhythms and multiplexed oscillatory sensory coding in the human brain. PLOS Biology, 11(12), e1001752. https://doi.org/10.1371/iournal.pbio.1001752 
Haegens, S., \& Zion Golumbic, E. (2018). Rhythmic facilitation of sensory processing: a critical review. Neuroscience \& Biobehavioral Reviews, 86, 150-165. https://doi.org/10.1016/j.neubiorev.2017.12.002

Harding, E. E., Sammler, D., Henry, M. J., Large, E. W., \& Kotz, S. A. (2019). Cortical tracking of rhythm in music and speech. NeuroImage, 185, 96-101. https://doi.org/10.1016/j.neuroimage.2018.10.037

Harms, M. P., Guinan, J. J., Jr, Sigalovsky, I. S., \& Melcher, J. R. (2005). Short-term sound temporal envelope characteristics determine multisecond time patterns of activity in human auditory cortex as shown by fMRI. Journal of Neurophysiology, 93(1), 210-222. https://doi.org/10.1152/in.00712.2004

Hasson, U., Chen, J., \& Honey, C. J. (2015). Hierarchical process memory: Memory as an integral component of information processing. Trends in Cognitive Sciences, 19(6), 304-313. https://doi.org/10.1016/j.tics.2015.04.006

Henin, S., Turk-Browne, N. B., Friedman, D., Liu, A., Dugan, P., Flinker, A., Doyle, W., Devinsky, O., \& Melloni, L. (2021). Learning hierarchical sequence representations across human cortex and hippocampus. Science Advances, 7(8), eabc4530. https://doi.org/10.1126/sciadv.abc4530

Henry, M. J., \& Obleser, J. (2012). Frequency modulation entrains slow neural oscillations and optimizes human listening behavior. Proceedings of the National Academy of Sciences of the United States of America, 109(49), 20095-20100. https://doi.org/10.1073/pnas.1213390109

Herholz, S. C., Boh, B., \& Pantev, C. (2011). Musical training modulates encoding of higher-order regularities in the auditory cortex. The European Journal of Neuroscience, 34(3), 3. https://doi.org/10.1111/j.1460-9568.2011.07775.x

Herholz, S. C., Lappe, C., \& Pantev, C. (2009). Looking for a pattern: an MEG study on the abstract mismatch negativity in musicians and nonmusicians. BMC Neuroscience, 10, 42. https://doi.org/10.1186/1471-2202-10-42

Herrmann, C. S., Strüber, D., Helfrich, R. F., \& Engel, A. K. (2016). EEG oscillations: From correlation to causality. International Journal of Psychophysiology, 103, 12-21. https://doi.org/10.1016/i.ijpsycho.2015.02.003 
Hirsh, I. J. (1959). Auditory perception of temporal order. The Journal of the Acoustical Society of America, 31(6), 759-767. https://doi.org/10.1121/1.1907782

Hoonhorst, I., Deltenre, P., Markessis, E., Collet, G., Pablos Martin, X., \& Colin, C. (2012). Evidence for a dual versus single origin of the MMNs evoked by cued versus cueless deviants. Clinical Neurophysiology, 123(8), 1561-1567. https://doi.org/10.1016/j.clinph.2011.12.015

Hovsepyan, S., Olasagasti, I., \& Giraud, A.-L. (2020). Combining predictive coding and neural oscillations enables online syllable recognition in natural speech. Nature Communications, 11(1),

\section{7. https://doi.org/10.1038/s41467-020-16956-5}

Hyafil, A., Fontolan, L., Kabdebon, C., Gutkin, B., \& Giraud, A.-L. (2015). Speech encoding by coupled cortical theta and gamma oscillations. ELife, 4, e06213.

https://doi.org/10.7554/eLife.06213

Hyde, M. (1997). The N1 response and its applications. Audiology \& Neuro-Otology, 2(5), 281-307. https://doi.org/10.1159/000259253

Jääskeläinen, I. P., Ahveninen, J., Bonmassar, G., Dale, A. M., Ilmoniemi, R. J., Levänen, S., Lin, F.-H., May, P., Melcher, J., Stufflebeam, S., Tiitinen, H., \& Belliveau, J. W. (2004). Human posterior auditory cortex gates novel sounds to consciousness. Proceedings of the National Academy of Sciences, 101(17), 6809-6814. https://doi.org/10.1073/pnas.0303760101

Kaernbach, C. (1993). Temporal and spectral basis of the features perceived in repeated noise. Journal of the Acoustical Society of America, 94(1), 91-97. https://doi.org/10.1121/1.406946

Kaernbach, C. (2004). The memory of noise. Experimental Psychology, 51(4), 240-248. https://doi.org/10.1027/1618-3169.51.4.240

Kaya, E. M., \& Elhilali, M. (2017). Modelling auditory attention. Philosophical Transactions of the Royal Society B: Biological Sciences, 372(1714), 20160101. https://doi.org/10.1098/rstb.2016.0101

Keitel, A., \& Gross, J. (2016). Individual human brain areas can be identified from their characteristic spectral activation fingerprints. PLOS Biology, 14(6), 6. https://doi.org/10.1371/iournal.pbio.1002498 
Keitel, A., Gross, J., \& Kayser, C. (2018). Perceptually relevant speech tracking in auditory and motor cortex reflects distinct linguistic features. PLOS Biology, 16(3), e2004473.

\section{https://doi.org/10.1371/journal.pbio.2004473}

Keitel, A., Ince, R. A. A., Gross, J., \& Kayser, C. (2016). Auditory cortical delta-entrainment interacts with oscillatory power in multiple fronto-parietal networks. NeuroImage. https://doi.org/10.1016/j.neuroimage.2016.11.062

Kiss, M., Cristescu, T., Fink, M., \& Wittmann, M. (2008). Auditory language comprehension of temporally reversed speech signals in native and non-native speakers. Acta Neurobiologiae Experimentalis, 68(2), 204-213.

Kohn, M., Lifshitz, K., \& Litchfield, D. (1978). Averaged evoked potentials and frequency modulation. Electroencephalography and Clinical Neurophysiology, 45(2), 236-243. https://doi.org/10.1016/0013-4694(78)90007-X

Kösem, A., Bosker, H. R., Takashima, A., Meyer, A., Jensen, O., \& Hagoort, P. (2018). Neural entrainment determines the words we hear. Current Biology, 28(18), 2867-2875.e3.

\section{https://doi.org/10.1016/j.cub.2018.07.023}

Kraus, N., Koch, D. B., McGee, T. J., Nicol, T. G., \& Cunningham, J. (1999). Speech-sound discrimination in school-age children: Psychophysical and neurophysiologic measures. Journal of Speech Language and Hearing Research, 42(5), 1042-1060. https://doi.org/10.1044/jslhr.4205.1042

Lakatos, P., Shah, A. S., Knuth, K. H., Ulbert, I., Karmos, G., \& Schroeder, C. E. (2005). An oscillatory hierarchy controlling neuronal excitability and stimulus processing in the auditory cortex. Journal of Neurophysiology, 94(3), 1904-1911. https://doi.org/10.1152/jn.00263.2005

Lerner, Y., Honey, C. J., Katkov, M., \& Hasson, U. (2014). Temporal scaling of neural responses to compressed and dilated natural speech. Journal of Neurophysiology, 111(12), 2433-2444. https://doi.org/10.1152/jn.00497.2013

Leung, S., Cornella, M., Grimm, S., \& Escera, C. (2012). Is fast auditory change detection feature specific? An electrophysiological study in humans. Psychophysiology, 49(7), 933-942. $\underline{\text { https://doi.org/10.1111/j.1469-8986.2012.01375.x }}$ 
Limbert, C. (1984). The perception of repeated noise. Unpublished doctoral dissertation. Cambridge University.

Llinás, R. R. (1988). The intrinsic electrophysiological properties of mammalian neurons: Insights into central nervous system function. Science, 242(4886), 1654-1664. https://doi.org/10.1126/science.3059497

Loveless, N. E., \& Hari, R. (1993). Auditory evoked fields covary with perceptual grouping. Biological Psychology, 35(1), 1-15. https://doi.org/10.1016/0301-0511(93)90088-P

Lubinus, C., Orpella, J., Keitel, A., Gudi-Mindermann, H., Engel, A. K., Roeder, B., \& Rimmele, J. M. (2021). Data-driven classification of spectral profiles reveals brain region-specific plasticity in blindness. Cerebral Cortex, 31(5), 2505-2522. https://doi.org/10.1093/cercor/bhaa370

Luo, H., \& Poeppel, D. (2007). Phase patterns of neuronal responses reliably discriminate speech in human auditory cortex. Neuron, 54(6), 1001-1010. https://doi.org/10.1016/j.neuron.2007.06.004

Luo, H., Tian, X., Song, K., Zhou, K., \& Poeppel, D. (2013). Neural response phase tracks how listeners learn new acoustic representations. Current Biology, 23(11), 968-974. https://doi.org/10.1016/j.cub.2013.04.031

Maiste, A., \& Picton, T. (1989). Human auditory evoked potentials to frequency-modulated tones. Ear and Hearing, 10(3), 153-160. https://doi.org/10.1097/00003446-198906000-00003

Martin, B. A., Tremblay, K. L., \& Korczak, P. (2008). Speech evoked potentials: from the laboratory to the clinic. Ear and Hearing, 29(3), 285-313. https://doi.org/10.1097/AUD.0b013e3181662c0e

Massaro, D. (1975). Experimental Psychology and Information Processing. Chicago: Rand McNally.

Massaro, D. W. (1970). Preperceptual auditory images. Journal of Experimental Psychology, 85(3),

\section{1-417. https://doi.org/10.1037/h0029712}

May, P. J. C., \& Tiitinen, H. (2010). Mismatch negativity (MMN), the deviance-elicited auditory deflection, explained. Psychophysiology, 47(1), 1. https://doi.org/10.1111/j.1469-8986.2009.00856.x

May, P., Tiitinen, H., Ilmoniemi, R. J., Nyman, G., Taylor, J. G., \& Näätänen, R. (1999). Frequency change detection in human auditory cortex. Journal of Computational Neuroscience, 6(2), 2. https://doi.org/10.1023/A:1008896417606 
McDermott, J. H., Schemitsch, M., \& Simoncelli, E. P. (2013). Summary statistics in auditory perception. Nature Neuroscience, 16(4), 493-498. https://doi.org/10.1038/nn.3347

McEvoy, L., Levänen, S., \& Loveless, N. (1997). Temporal characteristics of auditory sensory memory: neuromagnetic evidence. Psychophysiology, 34(3), 308-316. https://doi.org/10.1111/j.1469-8986.1997.tb02401.x

Meyer, L., Henry, M. J., Gaston, P., Schmuck, N., \& Friederici, A. D. (2017). Linguistic bias modulates interpretation of speech via neural delta-band oscillations. Cerebral Cortex, 27(9), 4293-4302. https://doi.org/10.1093/cercor/bhw228

Meyer, L., Sun, Y., \& Martin, A. E. (2020). Synchronous, but not entrained: Exogenous and endogenous cortical rhythms of speech and language processing. Language, Cognition and Neuroscience, 35(9), 1089-1099. https://doi.org/10.1080/23273798.2019.1693050

Micheyl, C., \& Oxenham, A. J. (2010). Pitch, harmonicity and concurrent sound segregation: psychoacoustical and neurophysiological findings. Hearing Research, 266(1-2), 36-51. https://doi.org/10.1016/i.heares.2009.09.012

Middlebrooks, J. C. (2005). Auditory cortex cheers the overture and listens through the finale. Nature Neuroscience, 8(7), 851-852. https://doi.org/10.1038/nn0705-851

Näätänen, R. (1992). Attention and brain function. Erlbaum.

Näätänen, R. (1995). The mismatch negativity: a powerful tool for cognitive neuroscience. Ear and Hearing, 16(1), 6-18.

Näätänen, R., Gaillard, A. W., \& Mäntysalo, S. (1978). Early selective-attention effect on evoked potential reinterpreted. Acta Psychologica, 42(4), 313-329. https://doi.org/10.1016/0301-0511(79)90053-X

Näätänen, R., Kujala, T., \& Winkler, I. (2011). Auditory processing that leads to conscious perception: a unique window to central auditory processing opened by the mismatch negativity and related responses. Psychophysiology, 48(1), 4-22. https://doi.org/10.1111/j.1469-8986.2010.01114.x

Näätänen, R., Paavilainen, P., \& Reinikainen, K. (1989). Do event-related potentials to infrequent decrements in duration of auditory stimuli demonstrate a memory trace in man? Neuroscience Letters, 107(1-3), 347-352. https://doi.org/10.1016/0304-3940(89)90844-6 
Näätänen, R., Paavilainen, P., Rinne, T., \& Alho, K. (2007). The mismatch negativity (MMN) in basic research of central auditory processing: a review. Clinical Neurophysiology, 118(12), 2544-2590. https://doi.org/10.1016/i.clinph.2007.04.026

Näätänen, R., \& Picton, T. (1987). The N1 wave of the human electric and magnetic response to sound: a review and an analysis of the component structure. Psychophysiology, 24(4), 375-425. https://10.1111/j.1469-8986.1987.tb00311.x

Näätänen, R., Syssoeva, O., \& Takegata, R. (2004). Automatic time perception in the human brain for intervals ranging from milliseconds to seconds. Psychophysiology, 41(4), 660-663. https://doi.org/10.1111/j.1469-8986.2004.00182.x

Näätänen, R., \& Winkler, I. (1999). The concept of auditory stimulus representation in cognitive neuroscience. Psychological Bulletin, 125(6), 826-859.

\section{https://doi.org/10.1037/0033-2909.125.6.826}

Neisser, U. (1967). Cognitive Psychology. Appleton-Century-Crofts.

Noda, K., Tonoike, M., Doi, K., Koizuka, I., Yoshida, H., Yamaguchi, M., Hamada, T., Seo, R., \& Kubo, T. (1999). A pitch glide activates an intermediate response between auditory N1 and mismatch negativity. Neuroreport, 10(9), 1909-1912. https://doi.org/10.1097/00001756-199906230-00021

Oberauer, K. (2002). Access to information in working memory: Exploring the focus of attention. Journal of Experimental Psychology. Learning, Memory, and Cognition, 28(3), 411-421.

Oever, S. ten, \& Sack, A. T. (2015). Oscillatory phase shapes syllable perception. Proceedings of the National Academy of Sciences, 112(52), 15833-15837. https://doi.org/10.1073/pnas.1517519112

Oganian, Y., \& Chang, E. F. (2019). A speech envelope landmark for syllable encoding in human superior temporal gyrus. Science Advances, 5(11), eaay6279.

https://doi.org/10.1126/sciadv.aay6279

Overath, T., McDermott, J. H., Zarate, J. M., \& Poeppel, D. (2015). The cortical analysis of speech-specific temporal structure revealed by responses to sound quilts. Nature Neuroscience, 18(6), 903-911. https://doi.org/10.1038/nn.4021 
Paavilainen, P. (2013). The mismatch-negativity (MMN) component of the auditory event-related potential to violations of abstract regularities: a review. International Journal of Psychophysiology, 88(2), 109-123. https://doi.org/10.1016/.ijpsycho.2013.03.015

Paavilainen, P., Simola, J., Jaramillo, M., Näätänen, R., \& Winkler, I. (2001). Preattentive extraction of abstract feature conjunctions from auditory stimulation as reflected by the mismatch negativity (MMN). Psychophysiology, 38(2), 359-365.

Panzeri, S., Brunel, N., Logothetis, N. K., \& Kayser, C. (2010). Sensory neural codes using multiplexed temporal scales. Trends in Neurosciences, 33(3), 111-120. https://doi.org/10.1016/j.tins.2009.12.001

Park, H., Ince, R. A. A., Schyns, P. G., Thut, G., \& Gross, J. (2015). Frontal top-down signals increase coupling of auditory low-frequency oscillations to continuous speech in human listeners. Current Biology: CB, 25(12), 1649-1653. https://doi.org/10.1016/j.cub.2015.04.049

Parras, G. G., Casado-Román, L., Schröger, E., \& Malmierca, M. S. (2021). The posterior auditory field is the chief generator of prediction error signals in the auditory cortex. NeuroImage, 242, 118446. https://doi.org/10.1016/j.neuroimage.2021.118446

Partanen, E., Vainio, M., Kujala, T., \& Huotilainen, M. (2011). Linguistic multifeature MMN paradigm for extensive recording of auditory discrimination profiles. Psychophysiology, 48(10), 1372-1380. https://doi.org/10.1111/j.1469-8986.2011.01214.x

Patterson, R. D., Milroy, R., \& Lutfi, R. A. (1983). Detecting a repeated tone burst in repeated noise. The Journal of the Acoustical Society of America, 73(3), 951-954.

\section{https://doi.org/10.1121/1.389019}

Peña, M., Bonatti, L. L., Nespor, M., \& Mehler, J. (2002). Signal-driven computations in speech processing. Science, 298(5593), 604-607. https://doi.org/10.1126/science.1072901

Phillips, D. P., Hall, S. E., \& Boehnke, S. E. (2002). Central auditory onset responses, and temporal asymmetries in auditory perception. Hearing Research, 167(1-2), 192-205. https://doi.org/10.1016/S0378-5955(02)00393-3

Pickles, J. O. (1988). An introduction to the Physiology of Hearing. Academic Press. 
Picton, T. W., Alain, C., Otten, L., Ritter, W., \& Achim, A. (2000). Mismatch negativity: different water in the same river. Audiology \& Neuro-Otology, 5(3-4), 111-139. https://doi.org/10.1159/000013875

Picton, T. W., Hillyard, S. A., Krausz, H. I., \& Galambos, R. (1974). Human auditory evoked potentials. I. Evaluation of components. Electroencephalography and Clinical Neurophysiology, 36(2), 179-190. https://doi.org/10.1016/0013-4694(74)90155-2

Picton, T. W., Woods, D. L., \& Proulx, G. B. (1978). Human auditory sustained potentials. I. The nature of the response. Electroencephalography and Clinical Neurophysiology, 45(2), 186-197. https://doi.org/10.1016/0013-4694(78)90003-2

Pikovsky, A., Rosenblum, M., \& Kurths, J. (2001). Synchronization: A universal concept in nonlinear sciences. Cambridge University Press. https://doi.org/10.1017/CBO9780511755743

Poeppel, D. (2003). The analysis of speech in different temporal integration windows: cerebral lateralization as 'asymmetric sampling in time.' Speech Communication, 4l(1), 245-255. https://doi.org/10.1016/S0167-6393(02)00107-3

Postle, B. R. (2006). Working memory as an emergent property of the mind and brain. Neuroscience, 139(1), 23-38. https://doi.org/10.1016/j.neuroscience.2005.06.005

Pulvermüller, F., Kujala, T., Shtyrov, Y., Simola, J., Tiitinen, H., Alku, P., Alho, K., Martinkauppi, S., Ilmoniemi, R. J., \& Näätänen, R. (2001). Memory traces for words as revealed by the mismatch negativity. Neuroimage, 14(3), 607-616. https://doi.org/10.1006/nimg.2001.0864

Pulvermüller, F., Shtyrov, Y., Kujala, T., \& Näätänen, R. (2004). Word-specific cortical activity as revealed by the mismatch negativity. Psychophysiology, 41(1), 106-112. https://doi.org/10.1111/j.1469-8986.2003.00135.x

Recasens, M., Grimm, S., Capilla, A., Nowak, R., \& Escera, C. (2014a). Two sequential processes of change detection in hierarchically ordered areas of the human auditory cortex. Cerebral Cortex, 24(1), 143-153. https://doi.org/10.1093/cercor/bhs295

Recasens, M., Grimm, S., Wollbrink, A., Pantev, C., \& Escera, C. (2014b). Encoding of nested levels of acoustic regularity in hierarchically organized areas of the human auditory cortex. Human Brain Mapping. https://doi.org/10.1002/hbm.22582 
Rimmele, J. M., Morillon, B., Poeppel, D., \& Arnal, L. H. (2018). Proactive sensing of periodic and aperiodic auditory patterns. Trends in Cognitive Sciences, 22(10), 870-882. https://doi.org/10.1016/j.tics.2018.08.003

Rimmele, J. M., Poeppel, D., \& Ghitza, O. (2021). Acoustically driven cortical $\delta$ oscillations underpin prosodic chunking. ENeuro, 8(4). https://doi.org/10.1523/ENEURO.0562-20.2021

Rimmele, J. M., Zion Golumbic, E., Schröger, E., \& Poeppel, D. (2015). The effects of selective attention and speech acoustics on neural speech-tracking in a multi-talker scene. Cortex, 68 , 144-154. https://doi.org/10.1016/j.cortex.2014.12.014

Ritter, W., Deacon, D., Gomes, H., Javitt, D. C., \& Vaughan, H. G., Jr. (1995). The mismatch negativity of event-related potentials as a probe of transient auditory memory: A review. Ear and Hearing, 16(1), 52-67. https://doi.org/10.1097/00003446-199502000-00005

Rosen, S. (1992). Temporal information in speech: Acoustic, auditory and linguistic aspects. Philosophical Transactions of the Royal Society of London. Series B, Biological Sciences, 336(1278), 367-373. https://doi.org/10.1098/rstb.1992.0070

Rüsseler, J., Altenmüller, E., Nager, W., Kohlmetz, C., \& Münte, T. F. (2001). Event-related brain potentials to sound omissions differ in musicians and non-musicians. Neuroscience Letters, 308(1), 33-36. https://doi.org/10.1016/s0304-3940(01)01977-2

Saberi, K., \& Perrott, D. R. (1999). Cognitive restoration of reversed speech. Nature, 398(6730), 760. https://doi.org/10.1038/19652

Salisbury, D. F. (2012). Finding the missing stimulus mismatch negativity (MMN): emitted MMN to violations of an auditory gestalt. Psychophysiology, 49(4), 544-548.

https://doi.org/10.1111/j.1469-8986.2011.01336.x

Sams, M., Alho, K., \& Näätänen, R. (1985). The Mismatch Negativity and Information Processing. In F. Klix, R. Näätänen, \& K. Zimmer (Eds.), Advances in Psychology (Vol. 25, pp. 161-176). North-Holland. https://doi.org/10.1016/S0166-4115(08)61602-7

Sams, M., Hari, R., Rif, J., \& Knuutila, J. (1993). The human auditory sensory memory trace persists about 10 sec: Neuromagnetic evidence. Journal of Cognitive Neuroscience, 5(3), 363-370. https://doi.org/10.1162/jocn.1993.5.3.363 
Sanders, L. D., Ameral, V., \& Sayles, K. (2009). Event-related potentials index segmentation of nonsense sounds. Neuropsychologia, 47(4), 1183-1186. https://doi.org/10.1016/j.neuropsychologia.2008.11.005

Sanders, L. D., \& Neville, H. J. (2003). An ERP study of continuous speech processing. I. Segmentation, semantics, and syntax in native speakers. Brain Research. Cognitive Brain Research, 15(3), 228-240. https://doi.org/10.1016/s0926-6410(02)00195-7

Sanders, L. D., Newport, E. L., \& Neville, H. J. (2002). Segmenting nonsense: An event-related potential index of perceived onsets in continuous speech. Nature Neuroscience, 5(7), 7. https://doi.org/10.1038/nn873

Sanders, L. D., \& Poeppel, D. (2007). Local and global auditory processing: Behavioral and ERP evidence. Neuropsychologia, 45(6), 1172-1186. https://doi.org/10.1016/j.neuropsychologia.2006.10.010

Schröger, E. (1994). An event-related potential study of sensory representations of unfamiliar tonal patterns. Psychophysiology, 31(2), 175-181. https://doi.org/10.1111/i.1469-8986.1994.tb01037.x

Schröger, E. (2007). Mismatch negativity—A microphone into auditory memory. Journal of Psychophysiology, 21(3-4), 138-146. https://doi.org/10.1027/0269-8803.21.34.138

Schröger, E., Bendixen, A., Denham, S. L., Mill, R. W., Bőhm, T. M., \& Winkler, I. (2014). Predictive regularity representations in violation detection and auditory stream segregation: From conceptual to computational models. Brain Topography, 27(4), 565-577. https://doi.org/10.1007/s10548-013-0334-6

Schröger, E., Näätänen, R., \& Paavilainen, P. (1992). Event-related potentials reveal how non-attended complex sound patterns are represented by the human brain. Neuroscience Letters, 146(2), 183-186. https://doi.org/10.1016/0304-3940(92)90073-g

Schröger, E., Paavilainen, P., \& Näätänen, R. (1994). Mismatch negativity to changes in a continuous tone with regularly varying frequencies. Electroencephalography and Clinical Neurophysiology, 92(2), 140-147. https://doi.org/10.1016/0168-5597(94)90054-x

Shinozaki, N., Yabe, H., Sato, Y., Hiruma, T., Sutoh, T., Matsuoka, T., \& Kaneko, S. (2003). Spectrotemporal window of integration of auditory information in the human brain. Brain 
Research. Cognitive Brain Research, 17(3), 563-571.

https://doi.org/10.1016/s0926-6410(03)00170-8

Singer, W. (2018). Neuronal oscillations: Unavoidable and useful? The European Journal of Neuroscience, 48(7), 2389-2398. https://doi.org/10.1111/ejn.13796

Stehwien, S., \& Meyer, L. (2021). Rhythm comes, rhythm goes: Short-term periodicity of prosodic phrasing. PsyArXiv. https://doi.org/10.31234/osf.io/c9sgb

Sussman, E., Kujala, T., Halmetoja, J., Lyytinen, H., Alku, P., \& Näätänen, R. (2004). Automatic and controlled processing of acoustic and phonetic contrasts. Hearing Research, 190(1-2), 128-140. https://doi.org/10.1016/S0378-5955(04)00016-4

Sussman, E. S., Chen, S., Sussman-Fort, J., \& Dinces, E. (2014). The five myths of MMN: redefining how to use MMN in basic and clinical research. Brain Topography, 27(4), 553-564. https://doi.org/10.1007/s10548-013-0326-6

Sussman, E. S., \& Gumenyuk, V. (2005). Organization of sequential sounds in auditory memory. Neuroreport, 16(13), 1519-1523. https://doi.org/10.1097/01.wnr.0000177002.35193.4c

Sussman, E., Winkler, I., Ritter, W., Alho, K., \& Näätänen, R. (1999). Temporal integration of auditory stimulus deviance as reflected by the mismatch negativity. Neuroscience Letters, 264(1-3), 161-164. https://doi.org/10.1016/s0304-3940(99)00214-1

Teng, X., Tian, X., Doelling, K., \& Poeppel, D. (2018). Theta band oscillations reflect more than entrainment: Behavioral and neural evidence demonstrates an active chunking process. The European Journal of Neuroscience, 48(8), 2770-2782. https://doi.org/10.1111/ejn.13742

Teng, X., Tian, X., \& Poeppel, D. (2016). Testing multi-scale processing in the auditory system. Scientific Reports, 6, 34390. https://doi.org/10.1038/srep34390

Tiitinen, H., May, P., Reinikainen, K., \& Näätänen, R. (1994). Attentive novelty detection in humans is governed by pre-attentive sensory memory. Nature, 372(6501), 90-92. https://doi.org/10.1038/372090a0

Timm, J., Weise, A., Grimm, S., \& Schröger, E. (2011). An asymmetry in the automatic detection of the presence or absence of a frequency modulation within a tone: A mismatch negativity study. Frontiers in Psychology, 2, 189. https://doi.org/10.3389/fpsyg.2011.00189 
Ueda, K., Nakajima, Y., Ellermeier, W., \& Kattner, F. (2017). Intelligibility of locally time-reversed speech: a multilingual comparison. Scientific Reports, 7(1), 1782. https://doi.org/10.1038/s41598-017-01831-Z

Ulanovsky, N., Las, L., Farkas, D., \& Nelken, I. (2004). Multiple time scales of adaptation in auditory cortex neurons. Journal of Neuroscience, 24(46), 10440-10453. https://doi.org/10.1523/JNEUROSCI.1905-04.2004

van Zuijen, T. L., Sussman, E., Winkler, I., Näätänen, R., \& Tervaniemi, M. (2004). Grouping of sequential sounds-An event-related potential study comparing musicians and nonmusicians. Journal of Cognitive Neuroscience, 16(2), 331-338. https://doi.org/10.1162/089892904322984607

Varnet, L., Ortiz-Barajas, M. C., Erra, R. G., Gervain, J., \& Lorenzi, C. (2017). A cross-linguistic study of speech modulation spectra. The Journal of the Acoustical Society of America, 142(4), 1976-1989. https://doi.org/10.1121/1.5006179

Vidal, Y., Brusini, P., Bonfieni, M., Mehler, J., \& Bekinschtein, T. A. (2019). Neural signal to violations of abstract rules using speech-like stimuli. ENeuro, 6(5). https://doi.org/10.1523/ENEURO.0128-19.2019

Wang, W., Datta, H., \& Sussman, E. (2005a). The development of the length of the temporal window of integration for rapidly presented auditory information as indexed by MMN. Clinical Neurophysiology, 116(7), 1695-1706. https://doi.org/10.1016/j.clinph.2005.03.008

Wang, X., Lu, T., Snider, R. K., \& Liang, L. (2005b). Sustained firing in auditory cortex evoked by preferred stimuli. Nature, 435(7040), 341-346. https://doi.org/10.1038/nature03565

Wark, B., Lundstrom, B. N., \& Fairhall, A. (2007). Sensory adaptation. Current Opinion in Neurobiology, 17(4), 423-429. https://doi.org/10.1016/i.conb.2007.07.001

Warren, R. M., \& Wrightson, J. M. (1981). Stimuli producing conflicting temporal and spectral cues to frequency. The Journal of the Acoustical Society of America, 70(4), 1020-1024. https://doi.org/10.1121/1.386952 
Watkins, M. J., \& Todres, A. K. (1980). Suffix effects manifest and concealed: Further evidence for a 20-second echo. Journal of Verbal Learning and Verbal Behavior, 19(1), 46-53. https://doi.org/10.1016/S0022-5371(80)90512-5

Weise, A., Bendixen, A., Müller, D., \& Schröger, E. (2012a). Which kind of transition is important for sound representation? An event-related potential study. Brain Research, 1464, 30-42. https://doi.org/10.1016/j.brainres.2012.04.046

Weise, A., Grimm, S., Müller, D., \& Schröger, E. (2010). A temporal constraint for automatic deviance detection and object formation: a mismatch negativity study. Brain Research, 1331, 88-95. https://doi.org/10.1016/j.brainres.2010.03.049

Weise, A., Grimm, S., Trujillo-Barreto, N. J. P., \& Schröger, E. (2014). Timing matters: The processing of pitch relations. Frontiers in Human Neuroscience, 8, 387. https://doi.org/10.3389/fnhum.2014.00387

Weise, A., Müller, D., Grimm, S., Rübsamen, R., \& Schröger, E. (2007). Differential processing of terminal tone parts within structured and non-structured tones. Neuroscience Letters, 421(2), 2. https://doi.org/10.1016/j.neulet.2007.05.029

Weise, A., Ritter, W., \& Schröger, E. (2011). The representation of unattended, segmented sounds: A mismatch negativity (MMN) study. International Journal of Psychophysiology, 81(2), 2. https://doi.org/10.1016/j.ijpsycho.2011.05.001

Weise, A., Schröger, E., Fehér, B., Folyi, T., \& Horváth, J. (2012b). Auditory event-related potentials reflect dedicated change detection activity for higher-order acoustic transitions. Biological Psychology, 91(1), 142-149. https://doi.org/10.1016/j.biopsycho.2012.06.001

Weise, A., Schröger, E., \& Horváth, J. (2018). The detection of higher-order acoustic transitions is reflected in the N1 ERP. Psychophysiology, 55(7), e13063. https://doi.org/10.1111/psyp. 13063

Winkler, I. (2007). Interpreting the mismatch negativity. Journal of Psychophysiology, 21(3-4), 147-163. https://doi.org/10.1027/0269-8803.21.34.147

Winkler, I., \& Cowan, N. (2005). From sensory to long-term memory: evidence from auditory memory reactivation studies. Experimental Psychology, 52(1), 3-20. https://doi.org/10.1027/1618-3169.52.1.3 
Winkler, I., \& Czigler, I. (1998). Mismatch negativity: deviance detection or the maintenance of the 'standard.' Neuroreport, 9(17), 3809-3813. https://doi.org/10.1097/00001756-199812010-00008

Winkler, I., Denham, S. L., \& Nelken, I. (2009). Modeling the auditory scene: Predictive regularity representations and perceptual objects. Trends in Cognitive Sciences, 13(12), 532-540. https://doi.org/10.1016/j.tics.2009.09.003

Winkler, I., Karmos, G., \& Näätänen, R. (1996). Adaptive modeling of the unattended acoustic environment reflected in the mismatch negativity event-related potential. Brain Research, 742(1-2), 239-252. https://doi.org/10.1016/s0006-8993(96)01008-6

Winkler, I., Korzyukov, O., Gumenyuk, V., Cowan, N., Linkenkaer-Hansen, K., Ilmoniemi, d R. J., Alho, K., \& Näätänen, R. (2002). Temporary and longer term retention of acoustic information. Psychophysiology, 39(4), 530-534. https://doi.org/10.1017.S0048577201393186

Winkler, I., \& Näätänen, R. (1992). Event-related potentials in auditory backward recognition masking: a new way to study the neurophysiological basis of sensory memory in humans. Neuroscience Letters, 140(2), 239-242. https://doi.org/10.1016/0304-3940(92)90111-i

Winkler, I., Reinikainen, K., \& Näätänen, R. (1993). Event-related brain potentials reflect traces of echoic memory in humans. Perception \& Psychophysics, 53(4), 443-449. https://doi.org/10.3758/bf03206788

Winkler, I., \& Schröger, E. (1995). Neural representation for the temporal structure of sound patterns. Neuroreport, 6(4), 690-694. https://doi.org/10.1097/00001756-199503000-00026

Winkler, I., \& Schröger, E. (2015). Auditory perceptual objects as generative models: setting the stage for communication by sound. Brain and Language, 148, 1-22. $\underline{\text { https://doi.org/10.1016/j.band1.2015.05.003 }}$

Winkler, I., Schröger, E., \& Cowan, N. (2001). The role of large-scale memory organization in the mismatch negativity event-related brain potential. Journal of Cognitive Neuroscience, 13(1), 59-71. https://doi.org/10.1162/089892901564171

Yabe, H., Asai, R., Hiruma, T., Sutoh, T., Koyama, S., Kakigi, R., Tervaniemi, M., \& Kaneko, S. (2004). Sound perception affected by nonlinear variation of accuracy in memory trace. Neuroreport, 15(18), 2813-2817. 
Yabe, H., Koyama, S., Kakigi, R., Gunji, A., Tervaniemi, M., Sato, Y., \& Kaneko, S. (2001).

Automatic discriminative sensitivity inside temporal window of sensory memory as a function of time. Brain Research, 12(1), 39-48. https://doi.org/10.1016/s0926-6410(01)00027-1

Yabe, H., Tervaniemi, M., Reinikainen, K., \& Näätänen, R. (1997). Temporal window of integration revealed by MMN to sound omission. Neuroreport, 8(8), 1971-1974. https://doi.org/10.1097/00001756-199705260-00035

Yabe, H., Tervaniemi, M., Sinkkonen, J., Huotilainen, M., Ilmoniemi, R. J., \& Näätänen, R. (1998). Temporal window of integration of auditory information in the human brain. Psychophysiology, 35(5), 615-619. https://doi.org/10.1017/s0048577298000183

Yamashiro, K., Inui, K., Otsuru, N., \& Kakigi, R. (2011). Change-related responses in the human auditory cortex: An MEG study. Psychophysiology, 48(1), 23-30. https://doi.org/10.1111/j.1469-8986.2010.01038.x

Yamashiro, K., Inui, K., Otsuru, N., Kida, T., \& Kakigi, R. (2009). Automatic auditory off-response in humans: an MEG study. The European Journal of Neuroscience, 30(1), 125-131. https://doi.org/10.1111/j.1460-9568.2009.06790.x

Yarden, T. S., Mizrahi, A., \& Nelken, I. (2022). Context-Dependent Inhibitory Control of Stimulus-Specific Adaptation. The Journal of Neuroscience: The Official Journal of the Society for Neuroscience, 42(23), 4629-4651. https://doi.org/10.1523/JNEUROSCI.0988-21.2022

Zion Golumbic, E. M., Ding, N., Bickel, S., Lakatos, P., Schevon, C. A., McKhann, G. M., Goodman, R. R., Emerson, R., Mehta, A. D., Simon, J. Z., Poeppel, D., \& Schroeder, C. E. (2013). Mechanisms underlying selective neuronal tracking of attended speech at a 'cocktail party.' Neuron, 77(5), 980-991. https://doi.org/10.1016/j.neuron.2012.12.037

Zwislocki, J. J. (1969). Temporal summation of loudness: an analysis. The Journal of the Acoustical Society of America, 46(2), 431-441. https://doi.org/10.1121/1.1911708 